\title{
Money to move: The effect on researchers of an international mobility grant
}

Citation for published version (APA):

Baruffaldi, S. H., Marino, M., \& Visentin, F. (2020). Money to move: The effect on researchers of an international mobility grant. Research Policy, 49(8), [104077]. https://doi.org/10.1016/j.respol.2020.104077

Document status and date:

Published: 01/10/2020

DOI:

10.1016/j.respol.2020.104077

Document Version:

Publisher's PDF, also known as Version of record

Document license:

Taverne

\section{Please check the document version of this publication:}

- A submitted manuscript is the version of the article upon submission and before peer-review. There can be important differences between the submitted version and the official published version of record.

People interested in the research are advised to contact the author for the final version of the publication, or visit the DOI to the publisher's website.

- The final author version and the galley proof are versions of the publication after peer review.

- The final published version features the final layout of the paper including the volume, issue and page numbers.

Link to publication

\footnotetext{
General rights rights.

- You may freely distribute the URL identifying the publication in the public portal. please follow below link for the End User Agreement:

www.umlib.nl/taverne-license

Take down policy

If you believe that this document breaches copyright please contact us at:

repository@maastrichtuniversity.nl

providing details and we will investigate your claim.
}

Copyright and moral rights for the publications made accessible in the public portal are retained by the authors and/or other copyright owners and it is a condition of accessing publications that users recognise and abide by the legal requirements associated with these

- Users may download and print one copy of any publication from the public portal for the purpose of private study or research.

- You may not further distribute the material or use it for any profit-making activity or commercial gain

If the publication is distributed under the terms of Article $25 \mathrm{fa}$ of the Dutch Copyright Act, indicated by the "Taverne" license above, 


\title{
Money to move: The effect on researchers of an international mobility grant
}

\author{
Stefano H. Baruffaldi ${ }^{\mathrm{a}, *, \#}$, Marianna Marino ${ }^{\mathrm{b}}$, Fabiana Visentin ${ }^{\mathrm{c}}$ \\ ${ }^{a}$ University of Bath, UK Max Planck Institute for Innovation and Competition, Germany \\ ${ }^{\mathrm{b}}$ SKEMA Business School, Université Côte d'Azur (GREDEG), France \\ ${ }^{\mathrm{c}}$ UNU-MERIT, Maastricht University, the Netherlands
}

\section{A B S T R A C T}

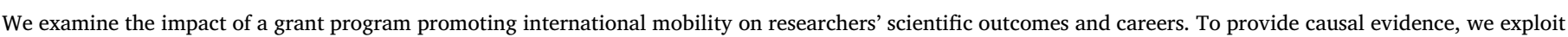

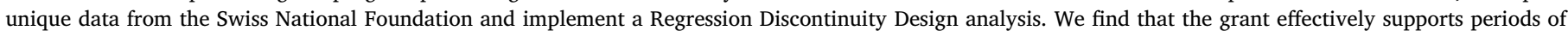

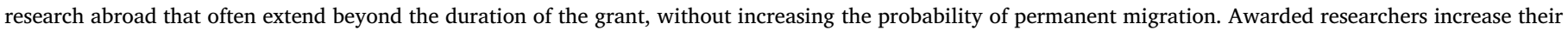

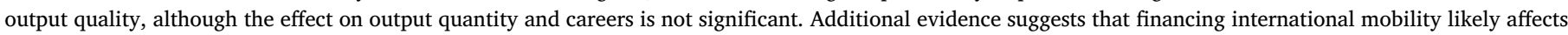

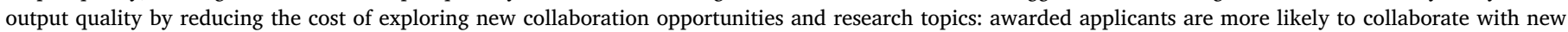

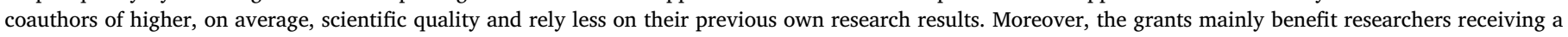
mobility grant for the first time.

\section{Introduction}

Highly skilled worker mobility has increased considerably in the last decades (Auriol, 2010; Saxenian, 2005, 2007). In particular, the academic sector has turned into a 'global market' of multicultural teams where foreign researchers often transit temporarily (Franzoni et al., 2012; Van Noorden, 2012). While the general phenomenon of permanent scientific migrations has often raised political concern (Adams and Douglas, 1968; Pierson and Cotgreave, 2000), several institutions and organizations have increasingly placed different forms of support to international temporal mobility at the center of their strategies to foster innovation (Meyer, 2003). The Fulbright Program in the United States or the Marie Curie fellowship in the European Union are notable examples, and have inspired several initiatives in other contexts. Despite the increasing presence of mobility programs within the portfolio of public funding agencies, there is still a limited understanding of their effects on scientists' productivity, careers, and modes of knowledge production. In a time of limited public resources and where the value of institutional efforts to promote international mobility is sometimes questioned, we deem important to understand the economic payoff of public financing in this domain.

Initiatives to support mobility often take the form of competitive grants offered to young researchers in the early and most crucial phases of their careers (Oyer, 2006; Stephan, 2012) to choose and spend a period in a different institution and country. In this paper, we provide causal evidence on the effect on researchers of one of these programs, the international mobility grant program sponsored by the Swiss National Science Foundation (SNFS). First, we assess the impact on short and medium-long term mobility. In the short term, we investigate if mobility grants crowd-out alternative funding for the same opportunities (Jaffe, 2002). Specifically, we want to measure the percentage of researchers who would not have moved abroad without the grant. In the medium-long term, we evaluate whether awarded applicants are more likely than non-awarded applicants to stay abroad beyond the duration of the grant. The temporal duration of the experience abroad has important implications. On one side, the prolongation of the period abroad can be seen favorably as the sign of a successful professional experience and higher propensity to remain mobile geographically (Parey and Waldinger, 2011). On the other side, an excessive incidence of permanent migration induced by the grant would raise the specter of "brain drain" (Gaulé, 2014; Oosterbeek and Webbink, 2011).

Second, we investigate the effect of the grant on scientific productivity and careers. We distinguish the effects on productivity in terms of quantity and quality. We assess the impact on careers by looking at the academic position of researchers over time. Third, and last, we explore the potential mechanisms altering the modes of knowledge production by focusing on changes in research network and research trajectory. Mobility often constitutes a process of networking and extending one's social and knowledge space (Ackers, 2005; Baruffaldi and Landoni, 2012; Saxenian, 2005). We argue that supporting mobility lowers the cost of exploring new collaboration opportunities and of entering in new high-quality research projects. In

\footnotetext{
* Corresponding author.

E-mail addresses: S.H.Baruffaldi@bath.ac.uk (S.H. Baruffaldi), marianna.marino@skema.edu (M. Marino), f.visentin@maastrichtuniversity.nl (F. Visentin).

\# Authors are in alphabetical order. All contributed equally.
} 
other words, supporting international mobility may serve as a mean of promoting the formation of professional ties with new collaborators in excellent research environments. Accordingly, we study whether awarded applicants have a higher chance of working with new coauthors of high scientific quality than non-awarded applicants, and we assess changes in research trajectories.

In our study, we use unique data on a mobility grant program awarded during the period 2003-2011 by the Swiss National Science Foundation (henceforth SNSF), the major institution financing research in Switzerland. The program finances research periods of up to a maximum of 36 months at a foreign research institution. During their stay abroad, researchers become fully affiliated with the host institute. While encouraged, return to Switzerland is not required. We collect detailed data and information on both awarded and non-awarded applicants. Confidential data provided by the SNSF on the selection process of candidates allows us to reconstruct the evaluation committee's ranking of candidates' proposals. We exploit a significant discontinuity in the probability of a grant being awarded along the evaluation committee's ranking and use a Regression Discontinuity Design (henceforth RDD) .

Our results show that awarded applicants are 47 percentage points (pp.) more likely to be abroad in the first year than non-awarded applicants. The effect of the grant extends beyond the duration of the grant itself, but the effect is reduced to $24 \mathrm{pp}$. five years later. For early cohorts, for which we can assess the probability of being abroad beyond the period of five years, this effect decreases further and tends to zero in the seventh year. We find significant and positive effects of being awarded in the output quality (average impact factor) but not in the output quantity (number of publications). We also do not observe significant effects on the likelihood of obtaining a professorship.

In terms of mechanisms, we provide evidence that being awarded a grant gives researchers access to a broader and better quality co-authorship network. Grant recipients have, on average, a $20 \mathrm{pp}$. higher share of new coauthors. Moreover, new coauthors of awarded applicants have, on average, publications of higher scientific quality. Importantly, the effect on the quality remains also if we exclude publications at or in collaboration with scientists of the host institution. This latter result demonstrates that the effect on quality extends beyond the specific period and network of collaborations at the host institution. Finally, awarded applicants rely less on previous own research results, as measured by the share of self-references in publications. However, we observe that they do not change the field of research. We conclude that mobility grants affect the scientific productivity of scientists by offering the opportunity to reach out to new colleagues and select collaborators that excel in their research field. By enlarging their network, awarded applicants are stimulated to invest in research project less related to their previous research, while remaining within their area of specialization.

Our study makes three main contributions. First, we contribute to studies relating to early mobility experience with later career choices. Parey and Waldinger (2011), analyzing the ERASMUS initiative, and Oosterbeek and Webbink (2011), with a study on a Dutch scholarship, find that experiencing a sponsored period abroad in the early stage of individuals' education increases the probability of working in a foreign country later after the studies. Differently from these studies, we consider the impact of mobility incentives to individuals at the early stages of their academic career, looking at a broad spectrum of outcomes. Doing so, we derive implications for individual professional performance in the sphere of knowledge production. Moreover, postdoctoral researchers represent a fundamental labor force for academic systems,

\footnotetext{
${ }^{1}$ The econometric methodology we apply allows for the estimation of causal effects locally (LATE), around the cut-off point of discontinuity in the probability of obtaining the grant, and is, therefore, relative to scientists of average quality in our sample.
}

constituting the base for future generations of scholars (Stephan, 2012).

Second, we add to the literature assessing the impact of public funding on researchers' productivity. The majority of existing studies have focused on general funding schemes (Arora and Gambardella, 2005; Azoulay et al., 2011; Gerritsen et al., 2013; Jacob and Lefgren, 2011; Lanser and van Dalen, 2013). As an exception, Kahn and MacGarvie (2012) analyze the Foreign Fulbright Program on the Science and Engineering field, exploring differences in productivity and return rates among students of different geographic origin. However, their study suffered the limitation of observing only awarded applicants. Thanks to our data, comprising information on all applicants, their full career history, and the committees' selection criteria, we can assess a causal effect. Moreover, we add to the literature discussing how the design of research grants impacts research trajectories. Recent studies note that the length and autonomy provided by different funding schemes determine the choice between exploration and exploitation and risk-taking behavior (Azoulay et al., 2011; Myers, 2018). Our results suggest that funding targeted to specific policy objectives, such as international mobility, may have analogous implications as they lower exploration costs for scientists.

Third, we contribute to the literature on academic mobility. Seminal contributions in this area have shown that mobile researchers have higher productivity (Franzoni et al., 2014; Gaulé and Piacentini, 2013; Hunter et al., 2009; Stephan and Levin, 2001), and broader international collaboration networks (Scellato et al., 2015) than non- mobile researchers. However, it remains unexplored what are the effects of financial support to mobility. Our quasi-experimental research design allows us to overcome the endogeneity issue associate with this policy question (Hoisl, 2007). In our case, a challenging task remains to analytically disentangle the effect of receiving economic support (money effect) from the mobility itself (mobility effect) since these two events co-occur. While we cannot fully address this issue, we find evidence supporting the prevalence of the role of mobility, and we discuss the mechanisms behind changes in the knowledge productivity function. In particular, we find that our results are mainly driven by the subset of researchers receiving a mobility grant for the first time.

\section{Institutional context}

According to the European Innovation Scoreboard (EIS), ${ }^{2}$ Switzerland is an innovation leader, outperforming all other European countries in terms of innovation capacities. One of the strengths of the country is the large number of PhDs: doctoral holders represent $1,8 \%$ of the total population and $2,8 \%$ of the total labor force, respectively (OECD, 2018). Switzerland is also one of the countries of the OECD area with the highest number of international students enrolled in Ph.D. programs. In 2017, the number of international students enrolled overcome the number of national students. Only Luxemburg is attracting a higher number of international students than Switzerland: $85 \%$ of the total versus $55 \%$, respectively. The Swiss research system appears among the most attractive countries for foreign researchers (Franzoni et al., 2012). Three Swiss institutions figure among the top 100 worldwide (QS World University Rankings), and 6 in the top 200. The ETH Zurich - Swiss Federal Institute of Technology is ranked 7th' placing Switzerland together with the US and UK in the set of countries with institutions listed among the top 10 . The high performance of the country in terms of doctoral training is complemented by a great variety of programs supporting postdoctoral studies. The Swiss National Science Foundation (SNSF) is the leading Swiss institution supporting national scientific research, playing the same role as the National Science Foundation in the US. The foundation allocates more than 150 CHF million per year, corresponding to $20 \%$ of its total budget, to

\footnotetext{
${ }^{2}$ See http://ec.europa.eu/growth/industry/innovation/facts-figures/ scoreboards/.
} 
promote young researchers' activities and careers. The "Advanced Postdoc Mobility" fellowships represent one of the flagship SNSF instruments supporting young researchers' experiences abroad.

Awarded researchers receive a scholarship to stay abroad at an institution of their choice and have the unique opportunity to access topranked universities worldwide. ${ }^{3}$ The grant covers a period of maximum 36 months and has to be spent in the foreign host institution indicated in the proposal. The SNSF encourages applicants to plan a return to Switzerland, but it is not a participation requirement, and awarded applicants are free to remain abroad beyond the SNSF grant duration; ${ }^{4}$ there are also no financial incentives targeted explicitly to the return of awarded applicants. Grant applications can be submitted two times during the year, the 1st of February or the 1st of August, respectively. Applicants should hold a doctoral degree, should demonstrate at least one year of research experience at the postdoctoral level, and should have Swiss nationality or proof of at least three years of activity at a Swiss research institution. On average, the SNSF receives 150 applications per year from applicants overall disciplines and selects over half of them.

Applicants' evaluation is centralized in Bern. The National Research Council (henceforth NRC) of the SNSF is responsible for the scientific evaluation of all applications. Applications in all disciplines are admitted and assigned for the evaluation to one of the three NRC divisions: (i) Humanities and Social Sciences, (ii) Mathematics, Natural and Engineering Sciences, and (iii) Biology. Fellowships in experimental and clinical medicine and basic medical science are evaluated externally by the Swiss Foundation for Grants in Biology and Medicine (SFGBM). Each commission is made by field experts appointed for periods of minimum five years. Each application is evaluated based on (i) the quality and originality of the research project, (ii) the applicant's scientific publication record, (iii) the applicant's career perspectives, (iv) the applicant's attitude versus her academic career and, (v) the quality of the hosting research institution proposed and its goodness of fit with the applicant's interests. Concerning this latter aspect, applicants are asked to carefully choose the host institution that represents the best fit for the accomplishment of their research proposal. Not only applicants need to motivate their host institution choice, but they also have to include in their application a confirmation letter from that host institution that the infrastructure needed for their research is available for the entire duration of the fellowship. This latter requirement ensures that applicants establish early direct contacts with the host institutions. In the evaluation procedure, the SNSF aims to follow the principles of excellence through competition, fairness, and equal opportunities. The NRC assigns to each application two external reviewers who are chosen for their expertise in the applicants' field. The external reviewers are asked to assign to the application evaluated a priority score on a scale of seven distinct values. ${ }^{5}$ Then, to select the best applications, the NRC collects the non-blind peer reviews, and during a general meeting, assigns a final score after having discussed and compared all the applications.

The analyzed Swiss grant has commonalities with programs offered

\footnotetext{
${ }^{3}$ The first top-10 most preferred destinations in our sample are: Harvard University, University of Cambridge, University of California Berkeley, the Max Planck Institute, Stanford University, Massachusetts Institute of Technology, University of Oxford, the Scripps Research Institute, California Institute of Technology, and University College of London. These are the preferred destinations for roughly the $25 \%$ of applicants. The total number of distinct host institutions indicated by applicants is 394 .

${ }^{4}$ From informal discussions at the SNSF we also learned that a temporary prolongation of the period abroad with external funding, perhaps from the host institution, is perceived as a positive outcome of the initial grant.

${ }^{5}$ The values are expressed as letters that goes from A to D where A is the maximum value, and intermediate values are admitted. The complete range of values results as follows: $\mathrm{A}, \mathrm{AB}, \mathrm{B}, \mathrm{BC}, \mathrm{C}, \mathrm{CD}$, and $\mathrm{D}$. In our analysis we convert the original alphabetical scale in numerical.
}

in other European countries. For example, it shares the dimension, selection process, and features with the post-doctoral fellowships sponsored by the Swedish Research Council, and the German Federal Ministry of Education and Research (BMBF). Each year, about 300 young Swedish scholars have the opportunity to stay at foreign universities or research establishments for up to 24 months (Swedish Research Council's website). The BMBF is supporting postdoctoral students for 12 months.

\section{Data}

\subsection{Data sources}

We combined different sources of data to create a unique dataset on awarded and non-awarded applicants. We obtained from the SNSF basic demographic information and information related to the grant applications for all applicants of "Advanced Postdoc Mobility" fellowships in the period 2003-2011. The SNSF data includes detailed information on the commission evaluating the applicants, the assigned score, and the final decision outcome. We integrated the information provided to us in an electronic format with data manually coded from the SNSF paper archives. We complemented the SNSF data with information on applicants' location and job position over time collected from applicants' CVs, LinkedIn, and personal webpages. Finally, we collected bibliometric data from the Scopus database. For each applicant, we manually collected her publication record and list of papers citing her work. Our initial sample included 1179 applicants. We dropped 47 cases due to missing information about the key variables, mainly the grade assigned to their applications. Our final sample consists of 1132 applicants. We grouped these applicants in 67 distinct cohorts, based on the date of their application and the assigned evaluation committee.

Applicants can reapply if they are not successful. However, this is rare, and happens only ten times in our sample, for applicants who applied a second time. Unsuccessful applicants often obtain alternative funding without the need to wait for a later application deadline. Moreover, the window of time after the Ph.D. in which researchers can access this funding scheme is narrow, so that it is likely that an unsuccessful applicant will not fall anymore in the professional age requirement at a later application opportunity. In our main analyses, we drop the first application for applicants that applied twice. The results remain stable, either we drop entirely the observations of applicants who applied twice, or we keep only the first application for those applicants.

\subsection{Variables}

Table 1 lists the variables included in our analysis with a short description of each of them. In our data, we observe the year in which all applicants intend to start their period abroad ("proposed year"), and we use this information to construct all time-variant variables by considering the "proposed year" as "the first year after the grant." First, we look at the location of the applicant at a specific point in time, and we construct the dummy variable that is equal to one if the applicant is abroad and zero if she is in Switzerland. In the main analysis, we consider the first (Abroad 1st year) and the fifth year (Abroad 5th year) after the grant. Then, to analyze changes in recipients' scientific knowledge production, we consider the applicant's publication record. In the main analysis, we count the cumulated number of publications from the first to the fifth year inclusive (Publications 5 years). Average JIF 5 years is the average impact factor of the journals where those publications appeared. ${ }^{6}$ To trace the job position, the dummy variable

\footnotetext{
${ }^{6}$ We run a separate set of regressions using citations as quality measure. Results are in line with the ones that consider the journal impact factor. Since the journal impact factor is not affected by truncations problems we decided to
} 
Table 1

Variables description.

\begin{tabular}{|c|c|}
\hline Variable & Description \\
\hline Grant awarded & Equal 1 if the applicant has obtained the mobility grant \\
\hline Grade (normalized) & The grade that the applicant has received on a scale from -4 to 3 (acceptance threshold equal 0 ) \\
\hline Abroad 1st year & Equal 1 if the applicant is abroad on the starting year \\
\hline Abroad 5th year & Equal 1 if the applicant is abroad on the fifth year \\
\hline Publications 5 years & Number of publications from the first year to the fifth year \\
\hline Average JIF 5 years & Average journal impact factor (JIF) of papers published from the first year to the fifth year \\
\hline Prof 5th year & Equal 1 if the applicant has a professor position on the fifth year \\
\hline New coauthors 5 years & Share of new coauthors from the first to the fifth year \\
\hline New coauthors JIF 5 years & Average quality of new coauthors acquired from the first to the fifth year \\
\hline Self-references 5 years & Share of references to own publications overall unique references in papers from the first to the fifth year \\
\hline Avg. JIF no host 5 years & Average JIF 5 years - excluding publications where the host city appears among the affiliation locations \\
\hline Foreign & Equal 1 if the applicant is foreign \\
\hline Female & Equal 1 if the applicant is female \\
\hline Age & Age of the applicant at the moment of the application \\
\hline Publications & Total number of publications at the moment of the application \\
\hline Citations & Average number of citations to publications at the moment of application. Citations counted in a 3-year window. \\
\hline Average JIF & Average journal impact factor (JIF) of papers published at the moment of application \\
\hline Coauthors & Total number of coauthors at the moment of the application \\
\hline Early mobility grants & Number of early mobility grants obtained before the application \\
\hline Rank Ph.D. university & Ranking of the university where the applicant obtained her/his $\mathrm{PhD}$ \\
\hline Rank host university & Ranking of the (proposed) host university \\
\hline Rank host res. institute & Ranking of the (proposed) host research institute \\
\hline Proposed duration & Duration proposed of the period abroad in months \\
\hline Amount request & Amount request in Swiss francs \\
\hline Dest. US & Equal 1 if the applicant indicated the US as a destination country \\
\hline Dest. UK & Equal 1 if the applicant indicated the UK as a destination country \\
\hline Dest. Germany & Equal 1 if the applicant indicated Germany as a destination country \\
\hline Dest. France & Equal 1 if the applicant indicated France as a destination country \\
\hline Dest. other & Equal 1 if the applicant indicated another country as a destination country \\
\hline
\end{tabular}

Prof 5th year is equal to one if the applicant obtains a professorship position in the fifth year after the grant.

As the main mechanism leading changes in the scientific outcomes, we look at the exploration of new collaboration opportunities. To this scope, we measure the extension of the applicant's co-authorship network (New coauthors 5 years) in terms of the share of unique new coauthors acquired by the applicant in the five years after the grant, i.e., those coauthors who appear in the applicants' publications only after the start of the grant. To compute the share, we divide the total number of new distinct coauthors acquired in the five years after the grant by the cumulative number of coauthors over the entire period of observation (before the grant and 5 years after the grant). ${ }^{7}$ To dig further into the mechanisms, we compute additional variables. We investigate the quality of the new coauthors, computing the average impact factor of the journals where a coauthor published before starting her collaboration with the focal researcher. ${ }^{8}$ Co-authors JIF 5 years is the average quality of new coauthors acquired in the 5-year period after the grant. ${ }^{9}$

\section{(footnote continued)}

keep the later one as main variable in the text. Results on citations are reported in the external appendix.

${ }^{7}$ The variable is computed only for applicants who had at least one publication at the moment of application. The impossibility to observe the starting moment of collaboration may induce measurement error, which, however, would bias both treated and controls around the cutoff similarly. As a robustness, to take into account larger delays between the start of collaboration and the observed publication, we lagged of one additional year the counting of the new co-authorships. The results are equivalent.

${ }^{8}$ We look at coauthors' publications in the 3-year window between 4 and 1 year before the first collaborative publication with the focal researcher. This period of choice relies on three main considerations. First, we need to measure coauthors' quality over publications that are not affected by the collaboration with the focal researcher. Second, we want to weight more the most recent research activities of new co-authors. Third, due to the large number of coauthors, we rely on the Scopus authors' identifiers for the disambiguation of names. Since, these identifiers may be less precise over long time periods a 3 years window reduces measurement error.
As an important robustness analysis, we explore the researcher's independent ability to publish in specific journals regardless of direct collaborations with colleagues in the host institution. After geocoding all affiliations in our sample, we compute the average impact factor of the journals where the applicant publishes excluding those publications where the same city of the host institution appears in the list of affiliations (Avg. JIF 5 years - no host). Finally, we proxy changes in research trajectories by an indicator capturing the extent to which new publications rely on previous research. We look at the publications' references in the 5 years after the grant and compute the share of selfreferences - defined as the set of references to the papers published by the focal applicant before the grant application (Self-references 5 years). The idea behind this measure is that a researcher refers to her previous publications when she directly exploits and follows-on previous work. Reducing the number of self-references is an indication that the researcher is exploring a different research trajectory.

As the demographic applicant's characteristics, we consider: the nationality of the applicant, distinguishing foreign applicants from Swiss applicants (Foreign); gender, a dummy variable equal to one for female researchers (Female); and the age of the applicant (Age). As indicators of the scientific productivity of the applicant, we consider the publication count (Publications), the average number of citations received over a 3 -year window by these publications ${ }^{10}$ (Citations) and the average impact factor (Average JIF) of the journals where the applicant published, at the moment of application. Additionally, we count the number of the applicant's distinct coauthors (Coauthors) at the moment of application. We are able to observe in our data whether an applicant received one or more early mobility grants before applying for the focal Advance mobility grant. In our analyses, we add a dummy (Early mobility grants), which equals one if the applicant received a mobility grant

\footnotetext{
${ }^{9}$ We find equivalent results using an alternative variable measuring the difference in average JIF between coauthors of the post-grant period and previous coauthors.

${ }^{10}$ As alternative we also used the total number of citations received by any publication up to the year of the application. Results were unchanged.
} 
Table 2

Variables descriptive statistics.

\begin{tabular}{|c|c|c|c|c|c|c|c|c|c|}
\hline \multirow[b]{2}{*}{ Variable } & \multicolumn{3}{|c|}{ All applicants } & \multicolumn{3}{|c|}{ Awarded applicants } & \multicolumn{3}{|c|}{ Non-awarded applicants } \\
\hline & Obs. & Mean & S.d. & Obs. & Mean & S.d. & Obs. & Mean & S.d. \\
\hline Grant awarded & 1132 & 0.70 & 0.46 & & & & & & \\
\hline Grade (normalized) & 1132 & 0.29 & 1.64 & 789 & 1.13 & 0.76 & 343 & -1.63 & 1.50 \\
\hline Abroad 1st year & 1132 & 0.81 & 0.40 & 789 & 0.96 & 0.20 & 343 & 0.46 & 0.50 \\
\hline Abroad 5th year & 1132 & 0.49 & 0.50 & 789 & 0.58 & 0.49 & 343 & 0.27 & 0.45 \\
\hline Publications 5 years & 1132 & 9.21 & 15.18 & 789 & 9.13 & 15.51 & 343 & 9.40 & 14.39 \\
\hline Average JIF 5 years & 1132 & 3.70 & 4.52 & 789 & 4.12 & 4.85 & 343 & 2.73 & 3.47 \\
\hline Prof 5th year & 1132 & 0.34 & 0.48 & 789 & 0.38 & 0.48 & 343 & 0.27 & 0.44 \\
\hline New coauthors 5 years* & 900 & 0.42 & 0.28 & 640 & 0.43 & 0.28 & 260 & 0.40 & 0.30 \\
\hline Coauthors JIF 5 years & 1132 & 2.17 & 2.55 & 789 & 2.42 & 2.72 & 343 & 1.61 & 1.98 \\
\hline Self-references 5 years & 1132 & 0.03 & 0.06 & 789 & 0.03 & 0.07 & 343 & 0.02 & 0.04 \\
\hline Avg. JIF 5 years - no host & 1132 & 2.09 & 3.23 & 789 & 2.35 & 3.52 & 343 & 1.47 & 2.35 \\
\hline Foreign & 1132 & 0.26 & 0.44 & 789 & 0.25 & 0.43 & 343 & 0.30 & 0.46 \\
\hline Female & 1132 & 0.34 & 0.47 & 789 & 0.32 & 0.47 & 343 & 0.37 & 0.48 \\
\hline Age & 1132 & 33.92 & 3.37 & 789 & 33.47 & 2.81 & 343 & 34.97 & 4.22 \\
\hline Publications & 1132 & 7.44 & 12.71 & 789 & 7.73 & 14.06 & 343 & 6.78 & 8.84 \\
\hline Citations & 1132 & 32.33 & 51.84 & 789 & 35.66 & 50.94 & 343 & 24.68 & 53.13 \\
\hline Average JIF & 1132 & 2.93 & 3.99 & 789 & 3.26 & 4.21 & 343 & 2.17 & 3.30 \\
\hline Coauthors & 1132 & 26.92 & 138.00 & 789 & 26.09 & 117.43 & 343 & 28.84 & 176.62 \\
\hline Early mobility grants & 1132 & 0.38 & 0.50 & 789 & 0.38 & 0.49 & 343 & 0.39 & 0.51 \\
\hline Rank PhD university & 1132 & 23.62 & 15.78 & 789 & 23.55 & 15.99 & 343 & 23.78 & 15.32 \\
\hline Rank host university & 1132 & 20.77 & 17.89 & 789 & 19.99 & 18.01 & 343 & 22.55 & 17.53 \\
\hline Rank host res. institute & 1132 & 67.61 & 11.14 & 789 & 67.77 & 10.85 & 343 & 67.23 & 11.78 \\
\hline Proposed duration & 1132 & 24.56 & 8.84 & 789 & 25.37 & 8.56 & 343 & 0.34 & 0.48 \\
\hline Amount request & 1132 & 116.97 & 49.92 & 789 & 120.57 & 46.58 & 343 & 0.10 & 0.30 \\
\hline Dest. US & 1132 & 0.07 & 0.26 & 789 & 0.39 & 0.49 & 343 & 0.09 & 0.29 \\
\hline Dest. UK & 1132 & 0.07 & 0.25 & 789 & 0.10 & 0.30 & 343 & 0.10 & 0.30 \\
\hline Dest. Germany & 1132 & 0.38 & 0.49 & 789 & 0.07 & 0.25 & 343 & 0.36 & 0.48 \\
\hline Dest. France & 1132 & 0.07 & 0.25 & 789 & 0.06 & 0.23 & 343 & 22.69 & 9.20 \\
\hline Dest. Other & 1132 & 0.38 & 0.49 & 789 & 0.39 & 0.49 & 343 & 108.70 & 56.08 \\
\hline
\end{tabular}

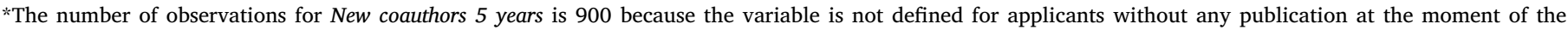
application.

in the past. We include the affiliation ranking of the university where the applicant obtained her Ph.D. (Rank Ph.D. university) and the ranking of the hosting university (Rank host university) or hosting research center (Rank host res. institute) as indicated in the grant proposal. To retrieve the ranking, we referred to the QS World University Rankings, and we considered the ranking of the affiliation in the field of specialization of the applicant. Finally, we consider the main application characteristics: the country destination designated in the application by the applicant; the proposed duration in months (Proposed duration); and the amount requested in Swiss francs (Amount requested). For the country destinations, we distinguish the main destination countries, i.e., the US, the UK, Germany, and France, and we group the remaining destinations in one unique residual category, Dest. Others.

Table 2 reports the summary statistics for our analysis sample. A quarter of the applicants in our sample are not Swiss. Thirty-four percent of them are female. Most individuals in our sample are young researchers with a successful record of publications at the moment of the application. Their average age is 34 . They have 7.44 publications, they receive 32.33 citations, and the journals in which they are publishing have an average impact factor of 2.93. The applicants in our sample also have relatively large coauthor networks, with more than 27 coauthors, on average. Thirty-eight percent of them benefited from an early mobility grant when applying for an advanced mobility grant. Sixty-five percent of applications are in the hard sciences, including engineering, life science, mathematics, medicine and health science, and natural science. The remaining $35 \%$ is in humanities and social science. Looking at the destination country, $38 \%$ of the applicants opt for an American research institute and about $40 \%$ for a country within Europe. The preferred destinations in Europe are the UK (7\%), Germany (7\%) and France (7\%). The proposed duration for staying abroad varies between 12 and 36 months, with the average duration being 25 months. The average amount requested for an application is approximately $\mathrm{CHF}$ 116,970 . In our sample, the success rate for grant applications is $71 \%$.

\section{Empirical strategy}

Grants are not randomly assigned since financial resources are limited and, on average, grants are assigned to individuals with better performance profiles. Those individuals with outstanding performance might have succeeded in their professional life, even without the grant. In our case, the descriptive statistics reported in Table 2 show that awarded applicants have a higher number of publications and, on average, publish in journals with a greater impact factor than nonawarded applicants. We follow previous studies evaluating government research subsidies (Howell, 2017; Zhao and Ziedonis, 2012) and, to correctly infer and isolate the impact of the grant on scientific outcomes, we exploit the richness of our data and implement an RDD approach. The RDD analysis requires the presence of a clear discontinuity in the probability of receiving the treatment (obtaining the grant) along with a so-called "assignment or forcing variable" (e.g., grade). Fig. 1 plots the probability of receiving the treatment as a function of the assigned grade.

As shown in Fig. 1, we observe a sharp discontinuity between the grade value -1 and 0 (Grade is normalized accordingly). The probability of obtaining the grant passes from about $11 \%$ to $78 \%$ for a proposal scoring -1 and 0 , respectively. The probability is 0 for grade values lower than -1 and close to $100 \%$ for a grade higher than 0 . Therefore, we adopt the value of 0 for the variable Grade as the cutoff point or threshold values of discontinuity. Due to a few exceptions, this discontinuity is not sharp. From discussions with the SNFS representatives, we verified that these exceptions are due to few cohorts where a limited (or excessive) number of applicants, relative to the available number of scholarships, permitted (prevented) to assign the grant to applicants below (above) the "usual" cutoff. Thus, we implement both a reduced-form RDD and a fuzzy RDD. ${ }^{11}$ For each one of our

\footnotetext{
${ }^{11}$ As robustness we verified that all results presented are qualitatively the
} 


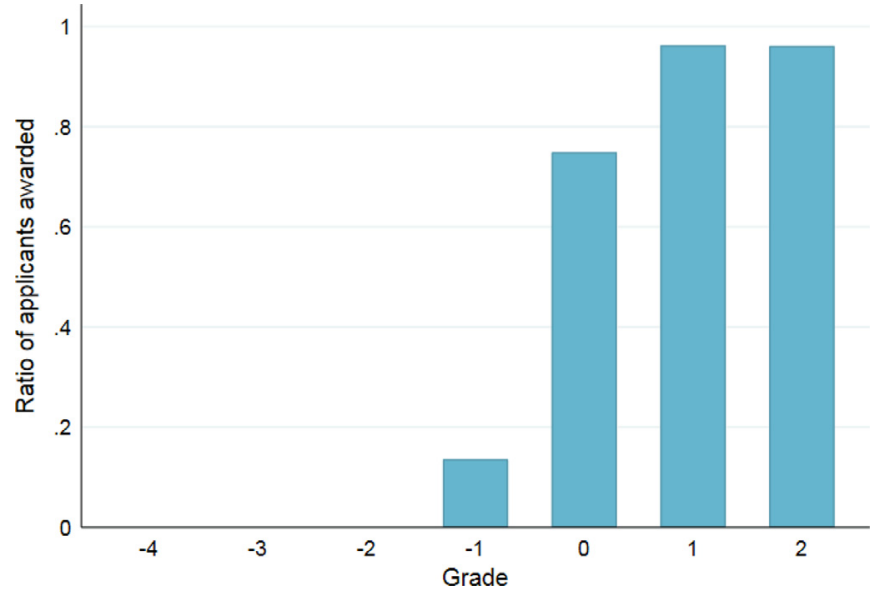

Fig. 1. Probability of obtaining the grant by Grade value.

Notes: The graph reports the ratio of awarded applicants by Grade value assigned to proposals. The probability of obtaining the grant is 0 for values of a Grade lower than -1 , it is about $10 \%$ for a value of -1 , and it is equal to or higher than $78 \%$ for values equal to or higher than 0 .

dependent variables, the RDD specification is:

$$
\begin{aligned}
Y_{i}= & \alpha_{i}+\beta I\left(\text { Grade }_{i}>\text { Treshold }+\gamma \text { Grade }_{i}+\delta I\left(\text { Grade }_{i}>\text { Treshold }\right)\right. \\
& * \text { Grade }_{i}+\omega X_{i}+\text { Cohorts }_{i}+\varepsilon_{i}
\end{aligned}
$$

where $Y_{i}$ is either (i) Abroad 1st year, (ii) Abroad 5th year, (iii) Publications 5 years, (iv) Average JIF 5 years, or v) Prof 5 th year. The coefficient of interest is $\beta$ capturing the effect of receiving a grade above the cutoff. To implement the RDD estimation, we include a two-sided linear trend control function of the assigned grade. In all specifications, we include commission dummies, as the grade can be interpreted as a relative ranking assigned by the examiners to the applicants within each commission. Also, the inclusion of commission dummies controls for differences associated with the broad scientific areas to which commissions are assigned. Subsequently, we introduce cohort fixed effects. A cohort identifies all the applicants submitting their applications to a certain commission at a given time and accounts for average differences across applicant cohorts over time and by commission. Finally, $X_{i}$ represents the vector of covariates including additional controls. Importantly, in the RDD framework, the controls are not necessary for identification but can improve the precision of the estimation. In particular, the pre-treatment values of the main outcome variables on productivity (Publications, Average JIF) and the number of coauthors (Coauthors) are suitable proxies for the quality of the applicant at the moment of application. To account for potential correlations in the error terms within cohorts, we cluster standard errors at the cohort level. The fuzzy RDD regression model requires the estimation of the following two-stage equation model:

$$
\begin{aligned}
\text { Grant }_{\text {awarded }}= & \alpha_{i}^{\prime}+\beta^{\prime} I\left(\text { Grade }_{i}>\text { Threshold }+\gamma^{\prime} \text { Grade }_{i}\right. \\
& +\delta^{\prime} I\left(\text { Grade }_{i}>\text { Threshold }^{*} \text { Grade }_{i}+\omega^{\prime} X_{i}+\text { Cohorts }_{i}\right. \\
& +\eta_{i}
\end{aligned}
$$

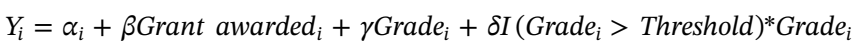

$$
+\omega X_{i}+\text { Cohorts }_{i}+\varepsilon_{i}
$$

In this specification, in the first-stage equation, $I\left(\right.$ Grade $_{i}>$ Treshold)

\section{(footnote continued)}

same using a RDD model on a sample where "fuzzy observations" are excluded: applicants with Grade lower than the threshold who obtained the grant and applicants with Grade higher than the threshold who did not obtain or used the grant. Results are available in the external appendix. functions as an instrument of the probability of receiving the grant. In the second-stage equation, the coefficient of interest $\beta$ can now be interpreted as the effect of receiving the grant. All other aspects of the model remain the same. In particular, the RDD identification assumption states, for both models, that by controlling for the appropriate function of the assignment variable (Grade), the dummy variable $I$ (Grade $_{i}>$ Threshold) is exogenous. The basic idea behind the RDD is that individuals who are ranked just below and above the cutoff have a reasonable degree of similarity (Angrist and Lavy, 1999; Black, 1999)

In our setting, the assignment variable is discrete and takes seven values. Using a finer-grained and more continuous assignment variable would be optimal and would allow us to control for more flexible functional forms of the variable. However, other empirical studies have used RD designs based on discrete assignment variables (Lalive and Parrotta, 2017; Ponzo and Scoppa, 2010). In our context, the ranking is applied to relatively small cohorts of applicants, only a few applicants (on average 4) concentrate around the acceptance threshold within each cohort. Most importantly, it remains possible to test the fundamental underlying assumption that, by controlling for our design function, applicants above and below the cutoff are comparable. We do this by regressing each of our covariates on our main RDD model with commission dummies. We report such a test graphically in Fig. 2 and analytically as a set of regressions in Appendix Table A-1. Fig. 2 shows the corresponding plots of the trends of control variables above and below the cutoff point. It can be noted that no selection occurs in almost all of the covariates, as the dummy variable I(Grade $>$ Threshold), within the RDD model has no residual significant correlation with any of these pre-determined variables. The only exceptions are for the variable that indicates whether the applicant has obtained in the past an early mobility grant. We verified through informal interviews that this could be explained by a tendency of the SNSF to finance more likely applicants who never received grants before. ${ }^{12}$ Based on the same interviews, we are confident that no other unobservable characteristics are likely to affect the decision, besides what is captured by the applicants' ranking. The SNFS is committed to maintaining high standards of fairness and transparency, and all documentation relative to the screening and evaluation of the proposal is at the disposal of applicants for scrutiny. Overall, this evidence supports the assumption that within our RDD model, the key background characteristics are balanced between awarded and non-awarded applicants, and that the RDD identification assumption holds.

\section{Econometric analyses}

We report the regression results for our main dependent variables from Tables 3-6. For each main outcome variable, we report five different models. In the first model, we present results for a simple OLS regression that estimates the descriptive difference between applicants above and below the acceptance threshold. In the second model, we present the basic RDD model, in which we control for a linear function of the grade with different slopes above and below the cutoff. In the third model, we add Cohorts FE and all of the controls. In the fourth model, we consider a regression model restricting the sample to observations with Grade values just above and below the acceptance threshold. Finally, in the fifth model, we report the results for the fuzzy RDD model with all controls. First-stage regression results for the fuzzy RDD model are reported in the appendix (Table A-2) and show that $I$ (Grade $>$ threshold) is a strong instrument for the probability of obtaining the grant. Estimates from the fuzzy RDD are generally larger in magnitude, as they reflect the results from the two-stage IV model and can be interpreted as the effect of actually receiving the grant.

Our empirical analysis is complemented by a graphical

\footnotetext{
${ }^{12}$ In Table 8, we estimate the effect of receiving the grant for these two groups separately.
} 

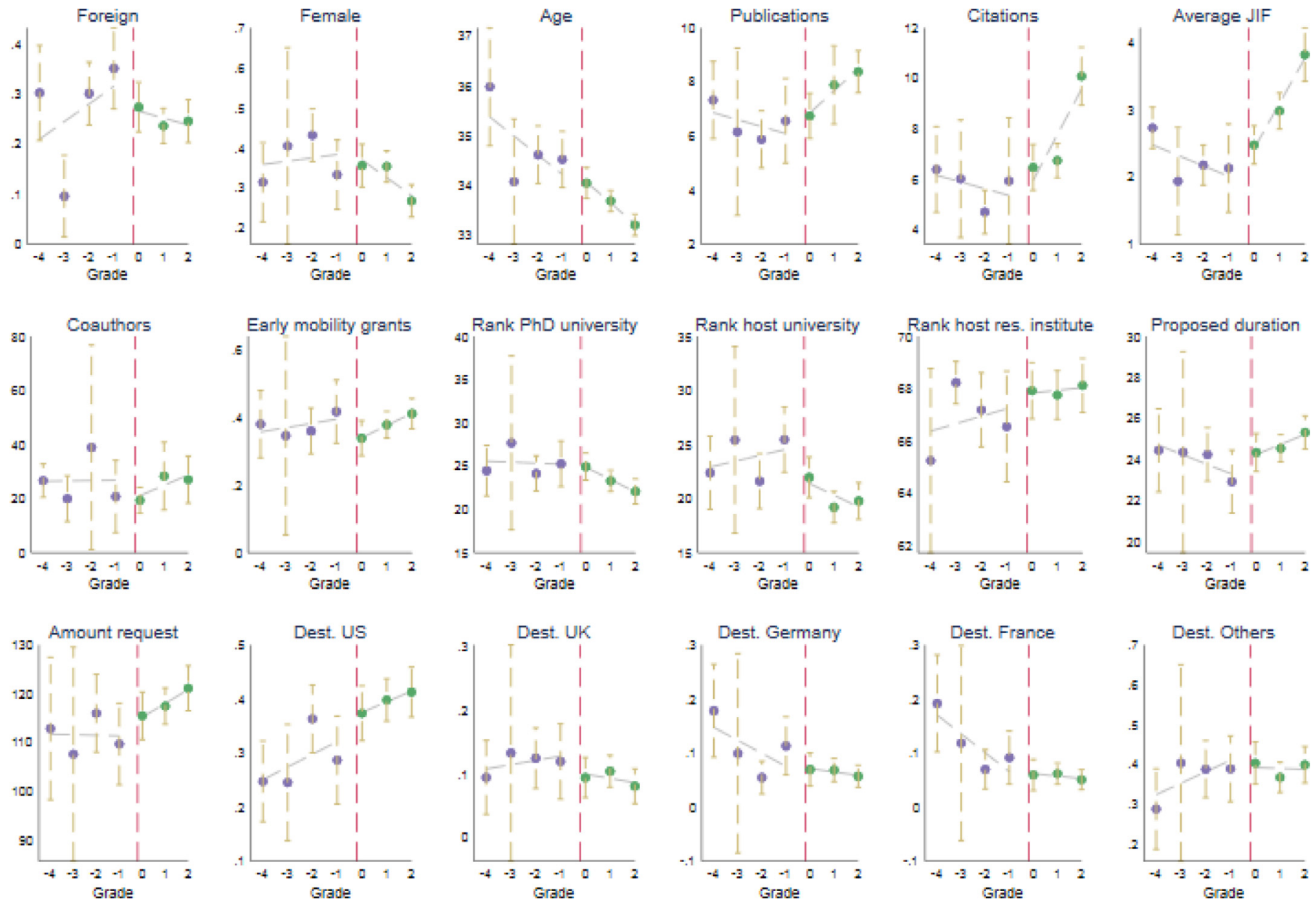

Fig. 2. RDD graphs on career and covariates.

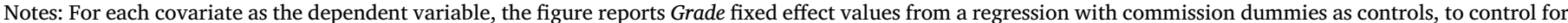

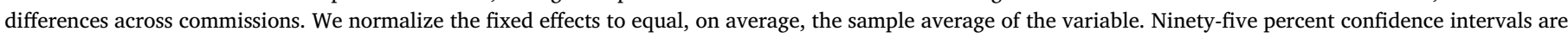
plotted. The vertical red dashed line highlights the point of discontinuity in the probability of obtaining the grant (Grade $=0$ ).

representation: Figs. 3-6 plot the mean, with 95\% confidence intervals, of the main outcome variables by Grade, the assignment variable. For publications, average JIF, and professor position, we plot Grade fixed effects from regressions with commission dummies to control for the heterogeneity across commissions. The cutoff point is highlighted by a vertical red dashed line.

\subsection{Effect on mobility: probability of being abroad}

Fig. 3 shows a sharp discontinuity in the probability of being abroad in the first year along with the grade values. Interestingly, a considerable share of the applicants below the cutoff point is also abroad in the first year. In the fifth year, the difference across the cutoff point is substantially reduced by a lower probability of the applicants above the cutoff of being abroad but remains qualitatively significant.

The regression results reported in Table 3 confirm a strong significant positive effect in the probability of being abroad in the first year across all the specifications. ${ }^{13}$ The fuzzy RDD model in column 5 suggests that awarded applicants are $47 \mathrm{pp}$. more likely to be abroad in

\footnotetext{
${ }^{13}$ The $5 \%$ of winners stay in Switzerland. A manual check of their CVs reveals that, of the corresponding 32 individuals, three renounced to the grant whereas the remaining individual temporal suspended it by postponing the departure. As robustness check, we run a separate set of regressions where we exclude those individuals. Results are consistent with the one reported, and available in the external appendix.
}

the first year: a large share of awarded applicants would not have moved abroad without the grant. In other words, the mobility grant, to a large extent, does not crowd-out alternative funding for the same opportunities. The effect on the probability of being abroad is substantially lower, but still weakly significant and positive, after 5 years, as awarded applicants are $24 \mathrm{pp}$. more likely to be abroad. This result is in line, in terms of magnitude, with previous studies related to students' mobility, and suggests that temporary mobility grants may facilitate longer or future new periods abroad (Parey and Waldinger, 2011).

From CV information, we observe qualitatively that applicants who remain abroad are able to do so thank to funding from abroad institutions. For the 2003-2010 cohorts of applicants, we can observe their outcomes variable beyond the 5 th year, up to the 7 th year. Results reported in Appendix A-3 show that the probability of being abroad decreases significantly over the years and become insignificant in the 7th year. Interestingly, looking at the non-returnees' profiles versus the others, we did not find significant differences in the scientific productivity of scientists staying abroad up to the 5th year.

Among the control variables, we find some predictable significant correlations: the likelihood of being abroad is lower for older applicants, and foreign applicants, as well as applicants who apply for more extended periods of stay, are more likely to be abroad in the 5th year. 
Table 3

Regression results on mobility.

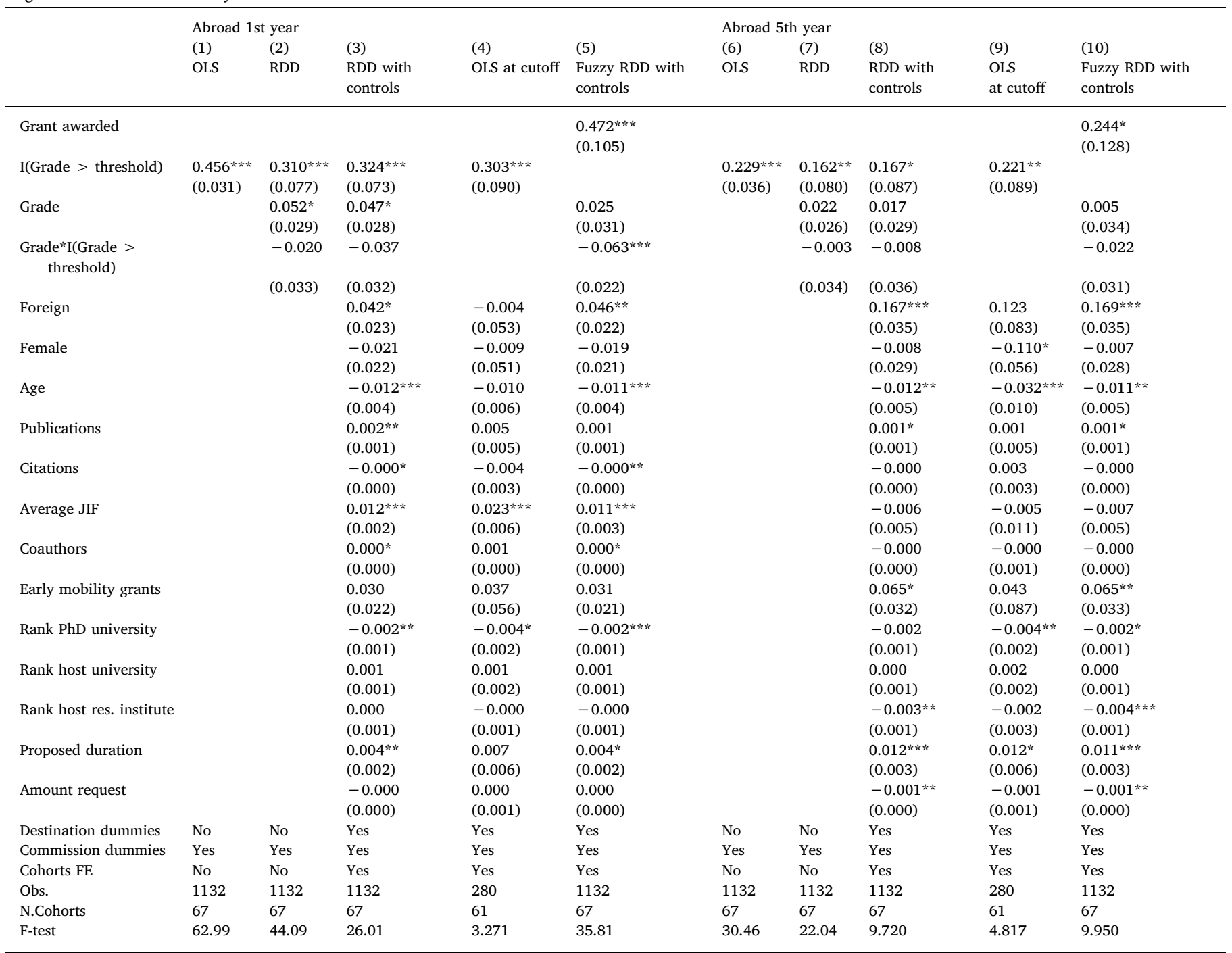

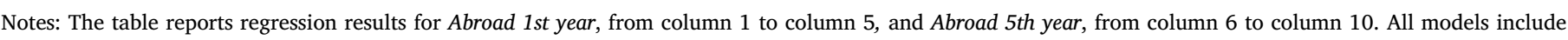

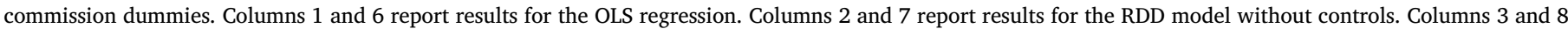

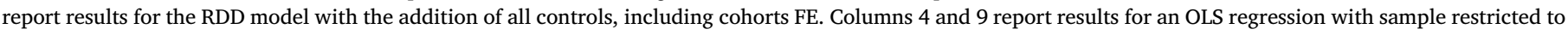

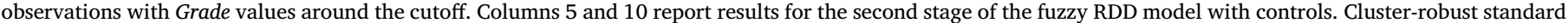
errors are in parentheses. ${ }^{* *} p<0.01,{ }^{* *} p<0.05,{ }^{*} p<0.1$.

\subsection{Scientific productivity and career}

\subsubsection{Scientific productivity}

Regarding the scientific productivity, in Fig. 4, we observe that scientific commissions, not surprisingly, tend to assign better grades to more productive applicants who likely continue to be relatively more productive after the grant application. However, accounting for this positive correlation, there is no visible difference between awarded and non-awarded applicants in terms of the number of publications, as there appears to be no discontinuity around the cutoff point. Looking at the average JIF, the positive shift above the cutoff point seems to indicate that awarded applicants have a greater chance of publishing in journals with a higher impact factor.

In Table 4, we report the corresponding econometric results. When we measure productivity as the number of publications in the 5 years following the grant, we do not find any significant effect. Remarkably, we find a positive and significant effect of receiving a grant on quality. The coefficients of interest on the average JIF of journals where applicants publish are positive and significant across all of the specifications. In terms of magnitude, the JIF increases by 1.37 points (Column 10, Table 4). We find predictable correlations concerning the control variable coefficients. In particular, the rank of the university of the Ph.D. and the host university is positively correlated ${ }^{14}$ with the number of publications after the grant and with the average JIF.

\subsubsection{Professorship}

Regarding the effect on the likelihood of being in a professorship position in the 5th year, in Fig. 5, only applicants with the maximum grade value (2) have a substantially higher probability of being professors (42\%). Comparing applicants around the cutoff point, there appears to be no difference.

In Table 5, in the OLS estimation (column 1), we find that applicants who obtain a grade higher than the cutoff are more likely to be in a professor position after 5 years from the grant. However, the models in

\footnotetext{
${ }^{14}$ Universities are ranked in ascending order, so that a negative coefficient implies that to higher ranked institutions correspond higher levels of the outcome variables.
} 

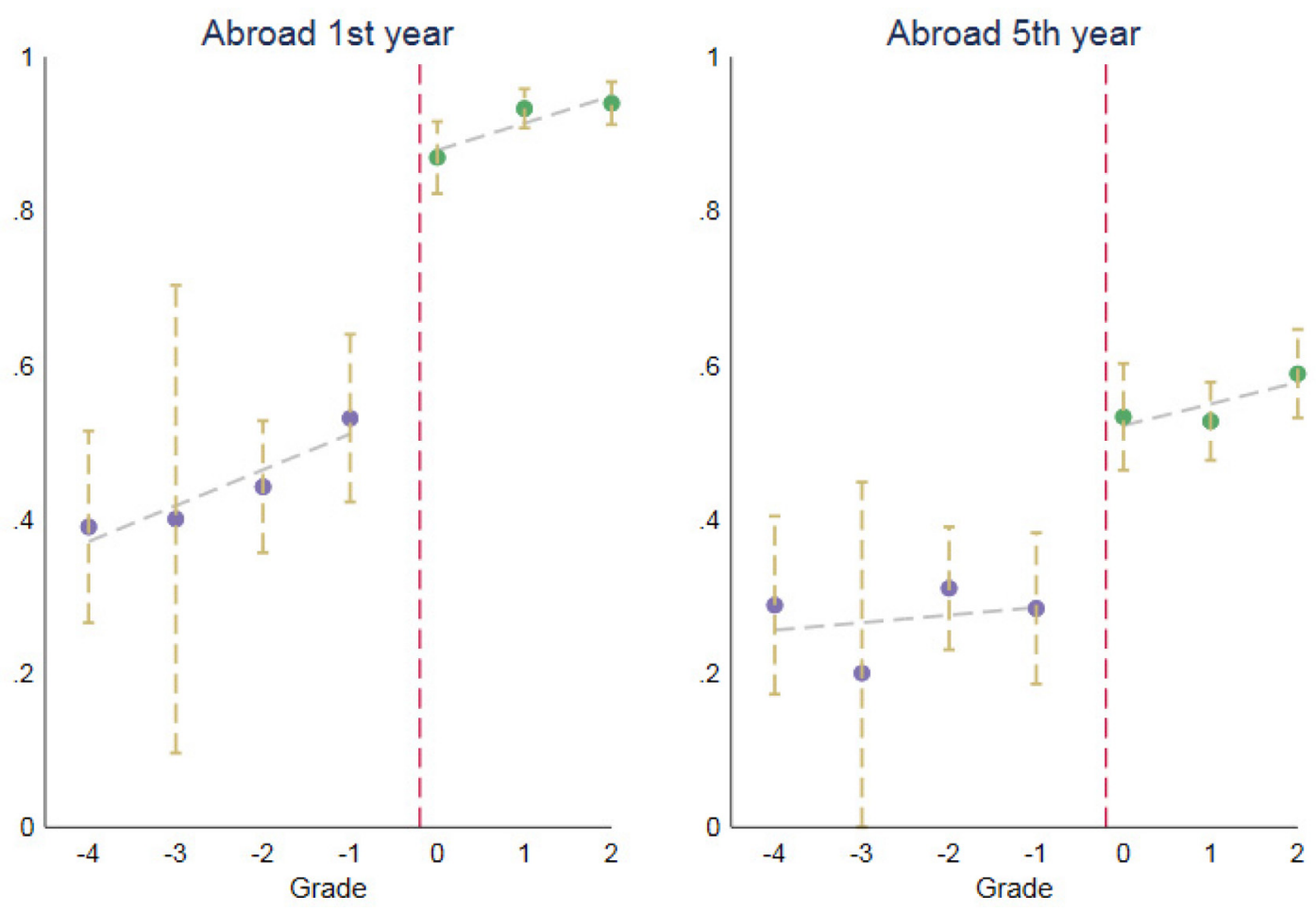

Fig. 3. RDD graphs on mobility

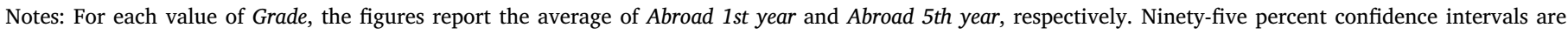
plotted. The vertical red dashed line highlights the point of discontinuity in the probability of obtaining the grant (Grade $=0$ ).
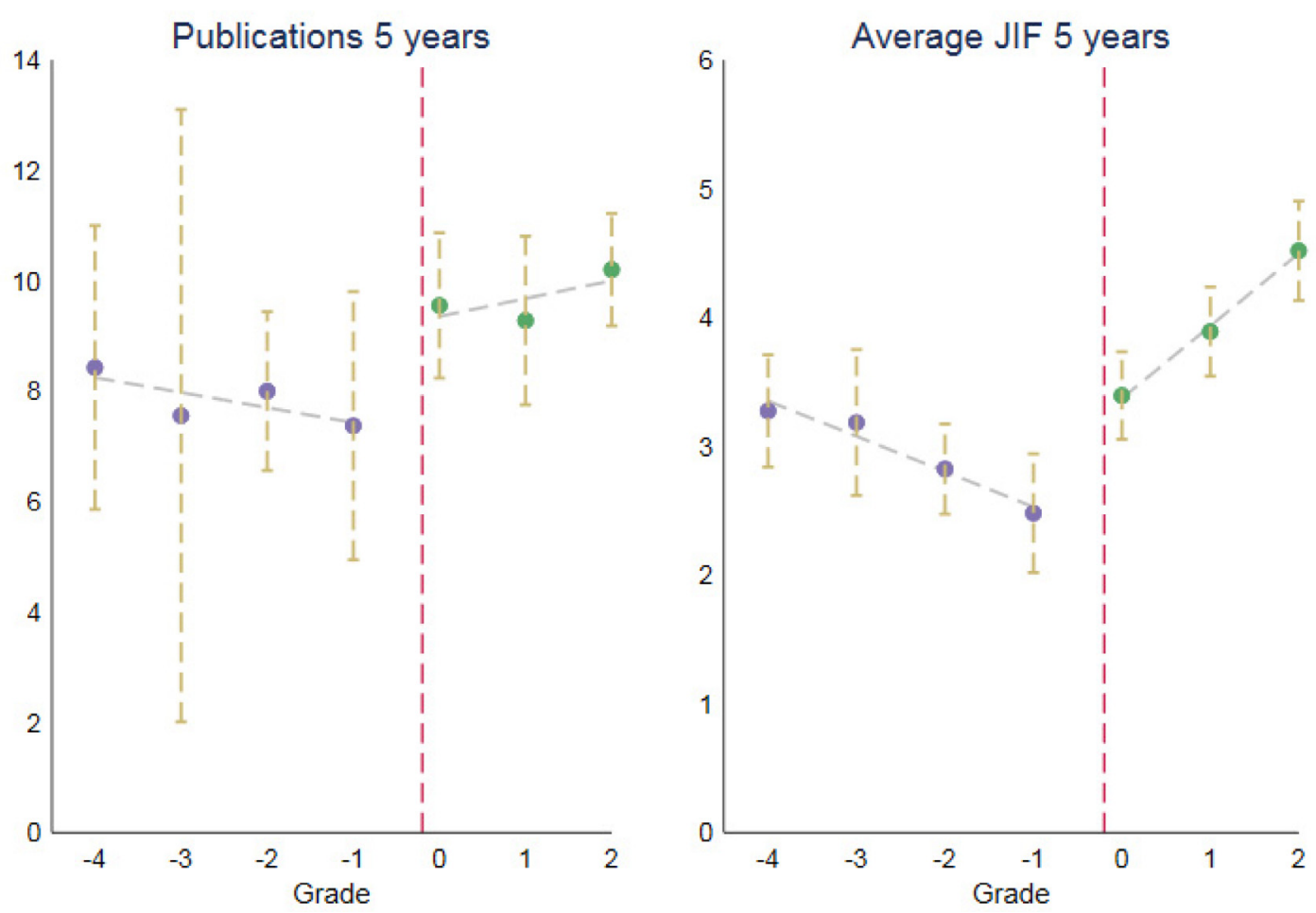

Fig. 4. RDD graphs on scientific productivity.

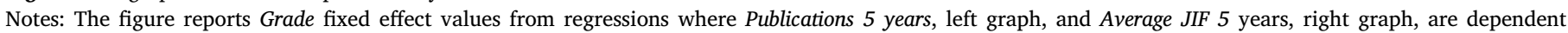

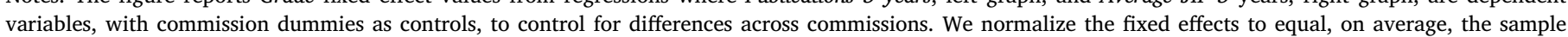

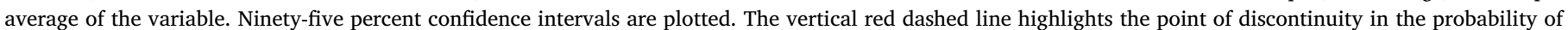
obtaining the grant (Grade $=0$ ). 
Table 4

Regression results on scientific productivity.

\begin{tabular}{|c|c|c|c|c|c|c|c|c|c|c|}
\hline & \multicolumn{5}{|c|}{ Publications 5 years } & \multicolumn{5}{|c|}{ Average JIF 5 years } \\
\hline & (1) & (2) & (3) & (4) & (5) & (6) & $(7)$ & $(8)$ & (9) & $(10)$ \\
\hline & OLS & RDD & $\begin{array}{l}\text { RDD with } \\
\text { controls }\end{array}$ & OLS at cutoff & $\begin{array}{l}\text { Fuzzy RDD with } \\
\text { controls }\end{array}$ & OLS & RDD & $\begin{array}{l}\text { RDD with } \\
\text { controls }\end{array}$ & OLS at cutoff & $\begin{array}{l}\text { Fuzzy RDD with } \\
\text { controls }\end{array}$ \\
\hline Grant awarded & & & & & $\begin{array}{l}3.838 \\
(2.731)\end{array}$ & & & & & $\begin{array}{l}1.368^{* *} \\
(0.573)\end{array}$ \\
\hline I(Grade > threshold) & $\begin{array}{l}1.694 \\
(1.078)\end{array}$ & $\begin{array}{l}0.791 \\
(1.929)\end{array}$ & $\begin{array}{l}2.629 \\
(1.873)\end{array}$ & $\begin{array}{l}1.144 \\
(1.708)\end{array}$ & & $\begin{array}{l}1.311^{* * *} \\
(0.231)\end{array}$ & $\begin{array}{l}0.952^{* *} \\
(0.419)\end{array}$ & $\begin{array}{l}0.937 * * \\
(0.386)\end{array}$ & $\begin{array}{l}0.661 * \\
(0.365)\end{array}$ & \\
\hline Grade & & $\begin{array}{l}0.272 \\
(0.711)\end{array}$ & $\begin{array}{l}-0.507 \\
(0.633)\end{array}$ & & $\begin{array}{l}-0.687 \\
(0.737)\end{array}$ & & $\begin{array}{l}-0.163 \\
(0.124)\end{array}$ & $\begin{array}{l}-0.213^{*} \\
(0.122)\end{array}$ & & $\begin{array}{l}-0.278^{* *} \\
(0.140)\end{array}$ \\
\hline $\begin{array}{c}\text { Grade* } \mathrm{I}(\text { Grade }> \\
\text { threshold })\end{array}$ & & $\begin{array}{l}0.031 \\
(0.868)\end{array}$ & (0.747) & & $\begin{array}{l}0.084 \\
(0.650)\end{array}$ & & $(0.221)$ & (0.195) & & $\begin{array}{l}0.238 \\
(0.205)\end{array}$ \\
\hline Foreign & & & $\begin{array}{l}-0.507 \\
(0.633)\end{array}$ & $\begin{array}{l}-0.750 \\
(1.547)\end{array}$ & $\begin{array}{l}-0.687 \\
(0.737)\end{array}$ & & & $\begin{array}{l}0.069 \\
(0.212)\end{array}$ & $\begin{array}{l}-0.174 \\
(0.282)\end{array}$ & $\begin{array}{l}0.079 \\
(0.207)\end{array}$ \\
\hline Female & & & $\begin{array}{l}0.295 \\
(0.747)\end{array}$ & $\begin{array}{l}-2.805^{* * *} \\
(0.967)\end{array}$ & $\begin{array}{l}0.084 \\
(0.650)\end{array}$ & & & $\begin{array}{l}0.014 \\
(0.213)\end{array}$ & $\begin{array}{l}-0.252 \\
(0.340)\end{array}$ & $\begin{array}{l}0.020 \\
(0.214)\end{array}$ \\
\hline Age & & & $\begin{array}{l}-0.716 \\
(0.675)\end{array}$ & $\begin{array}{l}-0.259 \\
(0.181)\end{array}$ & $\begin{array}{l}-0.688 \\
(0.662)\end{array}$ & & & $\begin{array}{l}-0.060 \\
(0.036)\end{array}$ & $\begin{array}{l}-0.038 \\
(0.039)\end{array}$ & $\begin{array}{l}-0.055 \\
(0.037)\end{array}$ \\
\hline Publications & & & $\begin{array}{l}-2.260^{* * *} \\
(0.665)\end{array}$ & $\begin{array}{l}0.779 * * * \\
(0.134)\end{array}$ & $\begin{array}{l}-2.246^{* * *} \\
(0.658)\end{array}$ & & & $\begin{array}{l}-0.007 \\
(0.007)\end{array}$ & $\begin{array}{l}0.044 * * \\
(0.019)\end{array}$ & $\begin{array}{l}-0.008 \\
(0.007)\end{array}$ \\
\hline Citations & & & $\begin{array}{l}-0.170^{*} \\
(0.095)\end{array}$ & $\begin{array}{l}-0.003 \\
(0.064)\end{array}$ & $\begin{array}{l}-0.155^{*} \\
(0.094)\end{array}$ & & & $\begin{array}{l}0.016^{* * *} \\
(0.004)\end{array}$ & $\begin{array}{l}0.051^{* * *} \\
(0.011)\end{array}$ & $\begin{array}{l}0.016^{* * *} \\
(0.004)\end{array}$ \\
\hline Average JIF & & & $\begin{array}{l}0.405^{* * *} \\
(0.133)\end{array}$ & $\begin{array}{l}0.079 \\
(0.216)\end{array}$ & $\begin{array}{l}0.402^{* * *} \\
(0.132)\end{array}$ & & & $\begin{array}{l}0.410^{* * *} \\
(0.055)\end{array}$ & $\begin{array}{l}0.338^{* * *} \\
(0.077)\end{array}$ & $\begin{array}{l}0.407^{* * *} \\
(0.054)\end{array}$ \\
\hline Coauthors & & & $\begin{array}{l}0.005 \\
(0.012)\end{array}$ & $\begin{array}{l}0.004 \\
(0.018)\end{array}$ & $\begin{array}{l}0.005 \\
(0.012)\end{array}$ & & & $\begin{array}{l}0.000 \\
(0.000)\end{array}$ & $\begin{array}{l}-0.002 \\
(0.002)\end{array}$ & $\begin{array}{l}0.000 \\
(0.000)\end{array}$ \\
\hline Early mobility grants & & & $\begin{array}{l}-0.085 \\
(0.124)\end{array}$ & $\begin{array}{l}1.588 \\
(1.369)\end{array}$ & $\begin{array}{c}-0.095 \\
(0.124)\end{array}$ & & & $\begin{array}{l}0.149 \\
(0.228)\end{array}$ & $\begin{array}{l}0.731^{* *} \\
(0.333)\end{array}$ & $\begin{array}{l}0.151 \\
(0.229)\end{array}$ \\
\hline Rank $\mathrm{PhD}$ university & & & $\begin{array}{l}0.037 \\
(0.029)\end{array}$ & $\begin{array}{l}-0.101^{*} \\
(0.052)\end{array}$ & $\begin{array}{l}0.037 \\
(0.029)\end{array}$ & & & $\begin{array}{l}-0.016^{\text {** }} \\
(0.006)\end{array}$ & $\begin{array}{l}-0.016 \\
(0.011)\end{array}$ & $\begin{array}{l}-0.018^{* * *} \\
(0.006)\end{array}$ \\
\hline Rank host university & & & $\begin{array}{l}-0.772 \\
(0.707)\end{array}$ & $\begin{array}{l}0.002 \\
(0.043)\end{array}$ & $\begin{array}{l}-0.766 \\
(0.719)\end{array}$ & & & $\begin{array}{l}-0.008^{*} \\
(0.005)\end{array}$ & $\begin{array}{l}-0.017^{*} \\
(0.009)\end{array}$ & $\begin{array}{l}-0.009^{*} \\
(0.005)\end{array}$ \\
\hline Rank host res. institute & & & $\begin{array}{l}-0.070^{* * * *} \\
(0.025)\end{array}$ & $\begin{array}{l}-0.019 \\
(0.031)\end{array}$ & $\begin{array}{l}-0.075^{* * *} \\
(0.026)\end{array}$ & & & $\begin{array}{l}-0.017 \\
(0.016)\end{array}$ & $\begin{array}{l}-0.022 \\
(0.017)\end{array}$ & $\begin{array}{l}-0.018 \\
(0.015)\end{array}$ \\
\hline Proposed duration & & & $\begin{array}{l}0.035 \\
(0.026)\end{array}$ & $\begin{array}{l}-0.140 \\
(0.109)\end{array}$ & $\begin{array}{l}0.034 \\
(0.026)\end{array}$ & & & $\begin{array}{l}0.001 \\
(0.015)\end{array}$ & $\begin{array}{l}0.094^{*} \\
(0.050)\end{array}$ & $\begin{array}{l}-0.001 \\
(0.015)\end{array}$ \\
\hline Amount request & & & $\begin{array}{l}0.048^{*} \\
(0.025)\end{array}$ & $\begin{array}{l}0.012 \\
(0.022)\end{array}$ & $\begin{array}{l}0.046^{*} \\
(0.024)\end{array}$ & & & $\begin{array}{l}0.004 \\
(0.003)\end{array}$ & $\begin{array}{l}-0.015 \\
(0.009)\end{array}$ & $\begin{array}{l}0.004 \\
(0.003)\end{array}$ \\
\hline Destination dummies & No & No & Yes & Yes & Yes & No & No & Yes & Yes & Yes \\
\hline Commission dummies & Yes & Yes & Yes & Yes & Yes & Yes & Yes & Yes & Yes & Yes \\
\hline Cohorts FE & No & No & Yes & Yes & Yes & No & No & Yes & Yes & Yes \\
\hline Obs. & 1132 & 1132 & 1132 & 280 & 1132 & 1132 & 1132 & 1132 & 280 & 1132 \\
\hline N.Cohorts & 67 & 67 & 67 & 61 & 67 & 67 & 67 & 67 & 61 & 67 \\
\hline F-test & 31.80 & 26.27 & 8.233 & 8.798 & 8.002 & 130 & 87.89 & 16.86 & 9.845 & 17.55 \\
\hline
\end{tabular}

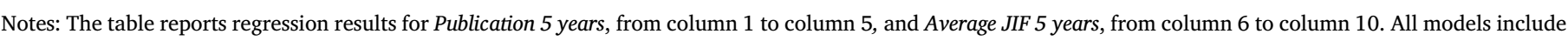

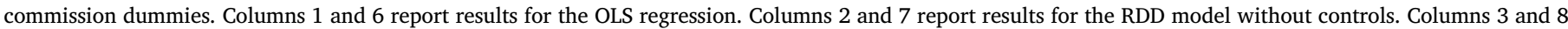

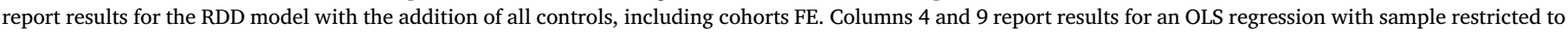

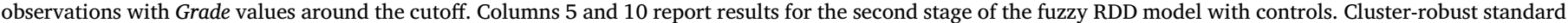
errors are in parentheses. ${ }^{* *} p<0.01,{ }^{* *} p<0.05,{ }^{*} p<0.1$.

columns 2 to 5 reveal that there is likely no causal effect of the grant; as in the RDD and fuzzy RDD models, the coefficients of interest are not significant and, if anything, are negative in sign. The control variables show a lower probability of female applicants obtaining a professorship position and a positive correlation with citations and the ranking of the host institute.

The non-significant result on the likely to obtain a professorship has to be taken with care. At the threshold of acceptance, the grant may not have relevance for professorship since few academic positions are available, and a relatively low share of applicants obtain a professorship position within our period of observation. Receiving the grant, and the observed increase in research quality for those recipients may still play a role for the best applicants, or in the long run. It is also interesting to consider that, a priori, being awarded might have both a positive and negative effect on obtaining a professorship. On the one hand, the mobility grant may have a signaling value that increases the probability of obtaining a position. On the other hand, granted applicants may have to delay the search for an academic position to complete their project, while not-granted applicants are stimulated to enter the job market soon. Moreover, some authors note how mobility may lead to the loss of local networks, which undermines or delays the search for academic positions in the country of residence, while new networks abroad may not immediately compensate (Ackers, 2005). In additional analyses, available upon request, we also investigated whether granted applicants were more likely to find positions at higher (or lower) ranked institutions. We do not find any significant results also on this dimension.

\subsection{Collaborations and topic exploration}

Having observed a positive effect of the grant on scientific productivity, we explore the potential mechanisms altering knowledge production. We assume that obtaining a mobility grant may affect knowledge production by lowering the costs of exploring new collaboration opportunities in high-quality research environments and of broadening the research portfolio.

In this section, we present evidence to support this assumption. First, we consider changes in the scientific network by looking at the 


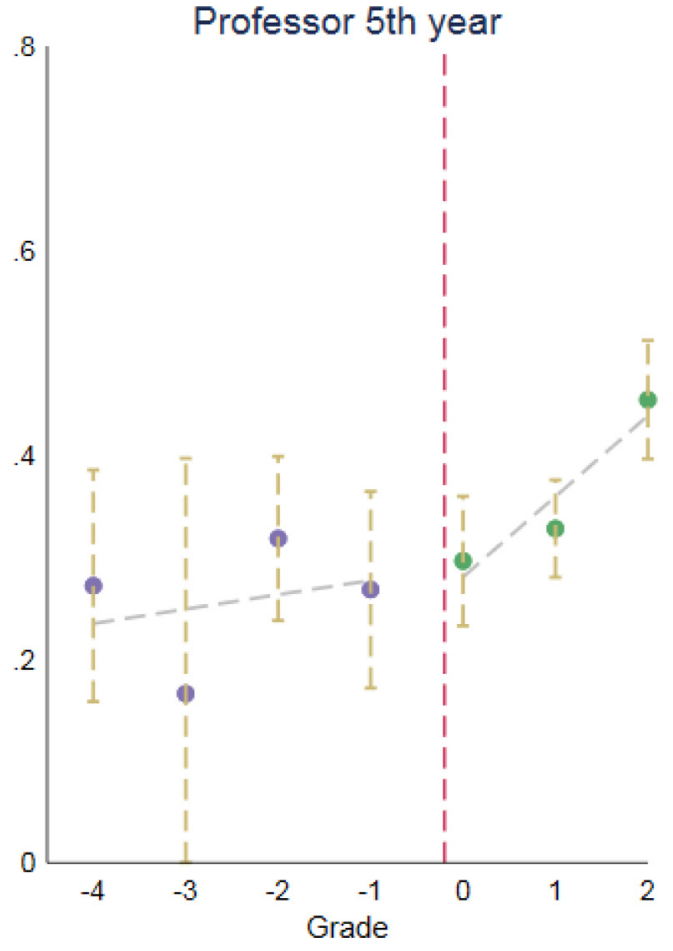

Fig. 5. RDD graph on career.

Notes: The figure reports Grade fixed effect values from a regression where Professor 5 years is the dependent variable and with commission dummies as controls, to control for differences across commissions. We normalize the fixed effects to equal, on average, the sample average of the variable. Ninety-five percent confidence intervals are plotted. The vertical red dashed line highlights the point of discontinuity in the probability of obtaining the grant (Grade $=0$ ).

share of new coauthors (see Fig. 6 and Table 6 for the corresponding results). Then, we complement this analysis with evidence on the scientific quality of new coauthors, the quality of applicants' publications independent from collaborations with the new coauthors, and indicators of the exploration of new research topics (see Table 7). For the sake of brevity, in Table 7 , we present only the main coefficients of interest for the second stage results of the fuzzy RDD model, including all controls and fixed effects.

\subsubsection{Network: share and quality of new coauthors}

Fig. 6 shows the descriptive evidence of the change in the share of new coauthors. The graph shows a positive shift. Table 6 reports the analysis of the number of new coauthors and shows a consistently positive coefficient of the variables of interest on the number of new coauthors. From column 5, we can quantify this effect as an increase of 20 pp. higher share of new coauthors for awarded applicants.

Furthermore, we explore whether awarded applicants work with new coauthors of higher scientific quality. Specifically, we use New coauthors JIF 5 years as the dependent variable. Empirical evidence, reported in Table 7, column 1, shows that grant awardees substantially improve the quality of their coauthors' network after the grant compared with non-awardees.

\subsubsection{Publications at the host institute affiliation}

Having observed the results on the share and quality of new coauthors, a possible concern might be that collaborations with scientists of high scientific quality during the visiting period in the host institution drive the findings on the average JIF. As robustness-check, to dispel this doubt, we look at the average JIF of publications excluding publications where the city of the host institution appears in the affiliation list. In other words, we disregard publications both during the stay in the host institution and in collaboration with scientists in the host
Table 5

Regression results on professorship.

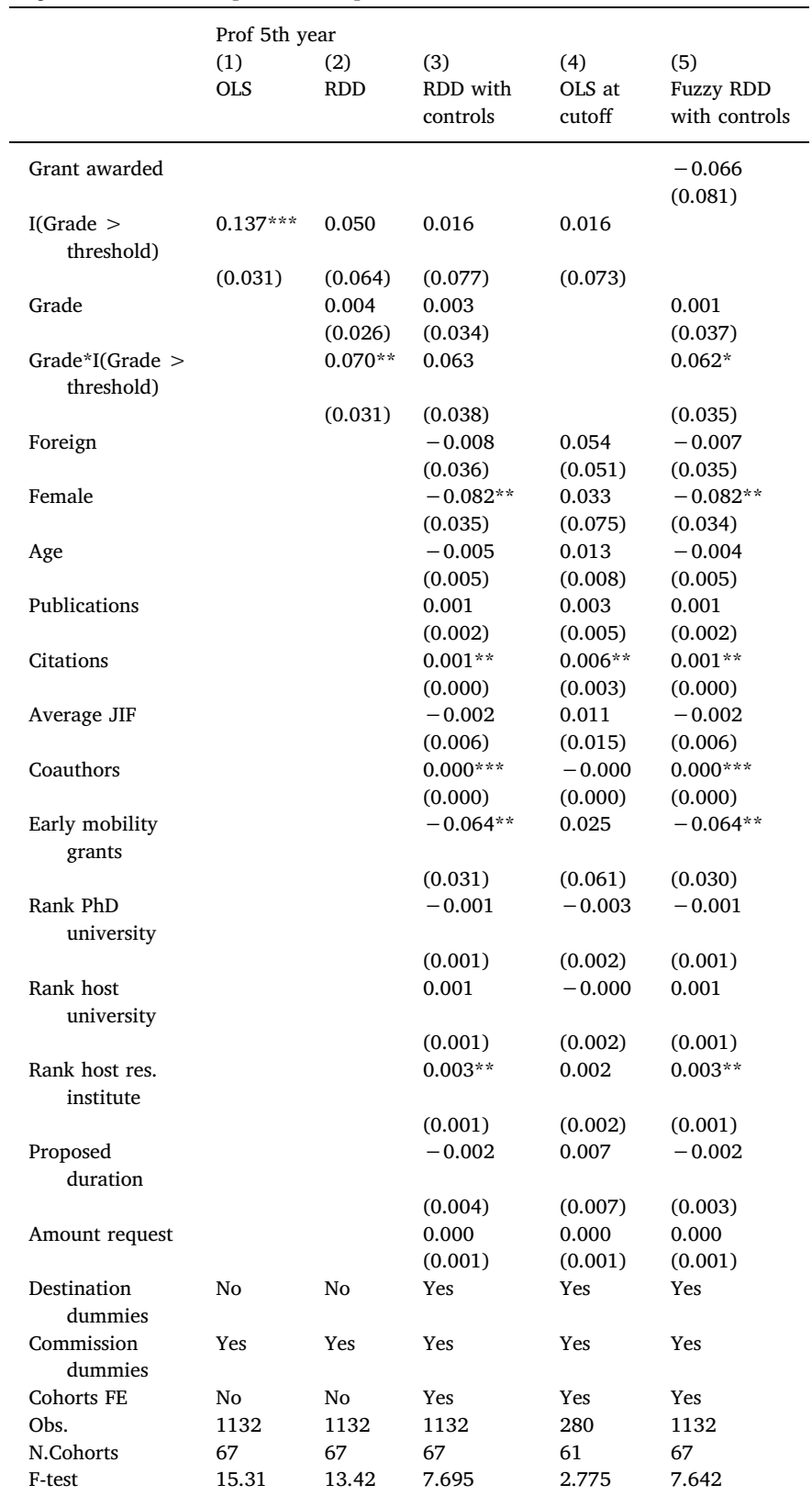

Notes: The table reports regression results for Prof 5 th years. All models include commission dummies. Columns 1 reports results for the OLS regression. Columns 2 reports results for the RDD model without controls. Columns 3 reports results for the RDD model with the addition of all controls, including cohorts FE. Columns 4 reports results for an OLS regression with sample restricted to observations with Grade values around the cutoff. Columns 5 reports results for the second stage of the fuzzy RDD model with controls. Clusterrobust standard errors are in parentheses. ${ }^{* * *} p<0.01,{ }^{* *} p<0.05,{ }^{*} p<0.1$.

institution. The results reported in Table 7, column 4, show that the effect on JIF remains positive. The impact is still weakly significant and positive when looking at the 5 -year period after the grant (Column 2) but remains more significant and stronger in magnitude in the 5 th year (Column 3). This result strengthens the idea that the benefits to awarded applicants go beyond the mere collaborations during the period in the host institution. The increase of the output quality seems to be explained by an effective learning effect and/or by a substantial effect on the quality of personal collaboration networks that extend beyond those directly associated with the period in the host institution. 


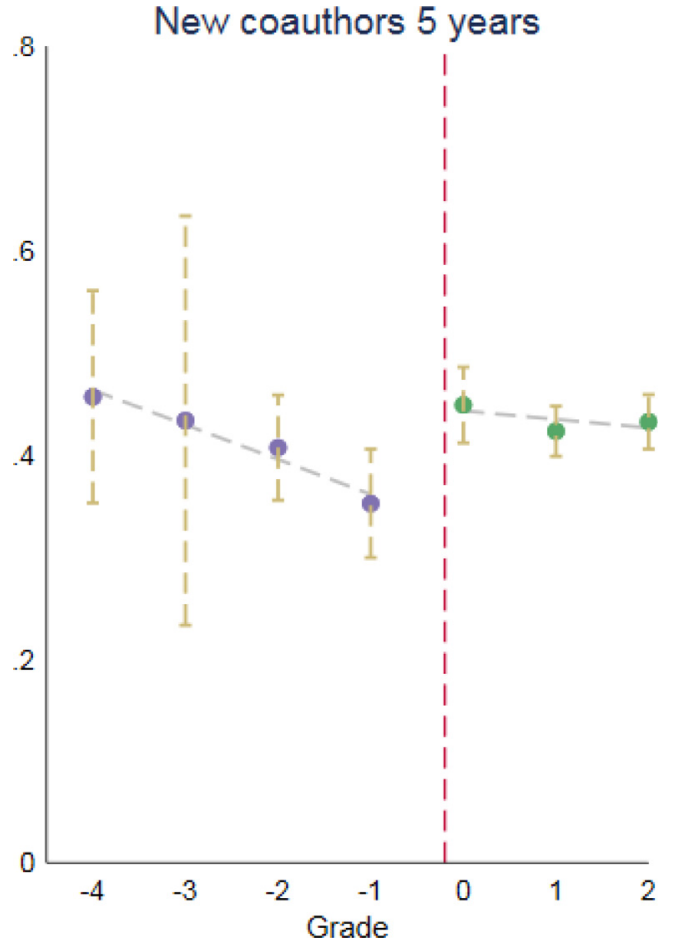

Fig. 6. RDD graph on networks.

Notes: The figure reports Grade fixed effect values from a regression where New coauthors 5 years is the dependent variable, with commission dummies as controls, to control for differences across commissions. We normalize the fixed effects to equal, on average, the sample average of the variable. Ninety-five percent confidence intervals are plotted. The vertical red dashed line highlights the point of discontinuity in the probability of obtaining the grant (Grade $=0$ ).

In a set of additional analyses, we explored the heterogeneity of the main results with respect to the ranking position of the university where applicants obtained their Ph.D. and the host institution ranking. We may expect stronger results for scientists hosted by highly ranked institutions (Fernández-Zubieta et al., 2016), especially if factors directly related to the institution, such as prestige and access to superior equipment, were the main mechanisms explaining the results. However, we do not find any significant variation across this dimension (results are available in the Appendixes A-3 and A-4, Table A-4 and Table A-5). On average, it remains that applicants spend the grant to reach out to excellent institutions. However, the results are comparable when applicants move to more highly ranked institutions as well as when they move to institutions of similar quality than the one of origin. This finding strengthens the idea that the support of the host institution per se does not fully explain our results.

\subsubsection{Exploration of new topics}

Having explored the changes in the new collaborations and their quality, we consider the exploration of new topics. In other words, we are interested in understanding whether new collaborations with coauthors of high scientific quality also correspond to a change in research trajectories. To do so, we use Self-references 5 years as the dependent variable. Arguably, a lower share of self-references in the publications of the later period would suggest that researchers are building marginally upon previous work to explore new topics. Column 4 of Table 7 shows that awarded applicants reduce their self-references by 2 pp., a magnitude quite substantial if we consider that the sample average for the indicator Self-reference is $3 \%$.

To complement this analytical finding, we looked descriptively at other aspects related to the research fields' exploration. We consider exploration across scientific fields counting the number of new four digits ASJC codes in publications appearing after the grant start year for
Table 6

Regression results on network.

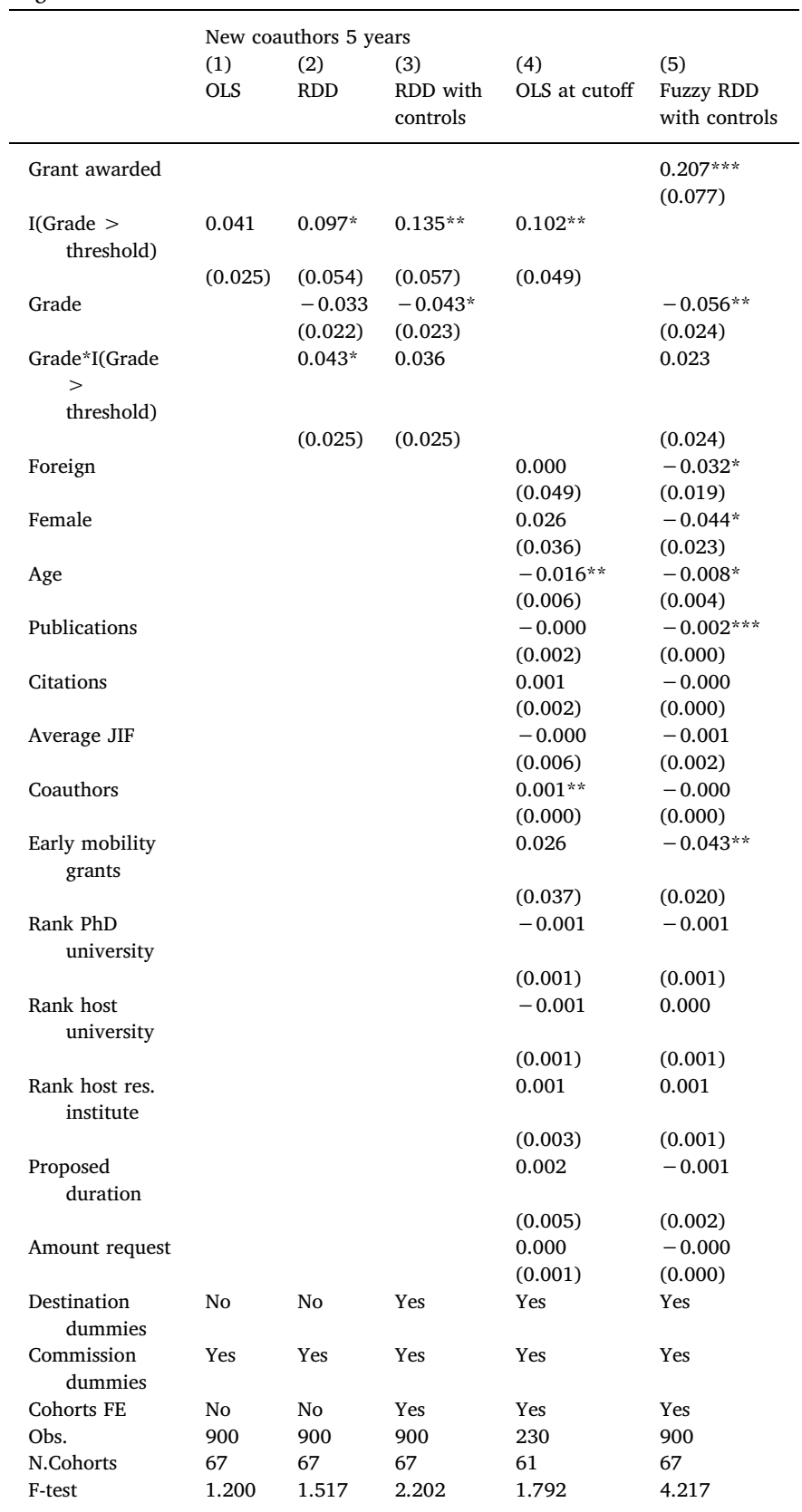

Notes: The table reports regression results for New coauthors 5 years. Columns 1 reports results for the OLS regression. Columns 2 reports results for the RDD model without controls. Columns 3 reports results for the RDD model with the addition of all controls, including cohorts FE. Columns 4 reports results for an OLS regression with sample restricted to observations with Grade values around the cutoff. Columns 5 reports results for the second stage of the fuzzy RDD model with controls. Cluster-robust standard errors are in parentheses. $* * *$ $p<0.01, * * p<0.05, * p<0.1$.

both the applicants and new coauthors. ${ }^{15}$ We found no significant differences. Applicants who received a grant publish on average in 1.5 new fields in the 5 years after the grant, as opposed to applicants who did not receive a grant who publish in 1.6 new fields. Similarly,

\footnotetext{
${ }^{15}$ We consider only codes where researchers (or co-authors) publish at least $5 \%$ of their publications to reduce noise. The results remain qualitatively the same when removing this restriction or weighting differently research fields, e.g. by the frequency of publications.
} 
Table 7

Digging into the mechanisms.

\begin{tabular}{lllll}
\hline & $\begin{array}{l}\text { (1) } \\
\text { New coauthors } \\
\text { JIF 5 years }\end{array}$ & $\begin{array}{l}(2) \\
\text { Avg. JIF no } \\
\text { host 5 years }\end{array}$ & $\begin{array}{l}\text { Avg. JIF no } \\
\text { host 5th year }\end{array}$ & $\begin{array}{l}\text { Self references } \\
5 \text { years }\end{array}$ \\
\hline Grant awarded & $\begin{array}{l}1.247^{* * *} \\
\text { (0.334) }\end{array}$ & $\begin{array}{l}0.728^{*} \\
(0.376)\end{array}$ & $\begin{array}{l}1.001^{* *} \\
(0.480)\end{array}$ & $\begin{array}{l}-0.024^{* *} \\
(0.011)\end{array}$ \\
Obs. & 1132 & 1132 & 1132 & 1132 \\
N.Cohorts & 67 & 67 & 67 & 67 \\
F-test & 13.24 & 5.807 & 4.381 & 5.415 \\
\hline
\end{tabular}

Notes: The table reports the coefficients for the variable Grant awarded variable. The dependent variable is New coauthors JIF 5 years in column 1, Avg. JIF no host 5 years in column 2, Avg. JIF no host 5th year in column 3 and, Self-references 5 years in column 4. Avg. JIF no host 5th is a variant of the variable Avg. JIF no host 5 years where we consider the average JIF of publications published on the 5 th year. All columns report results for the second stage of the fuzzy RDD model with controls. Cluster robust standard errors are in parentheses. $* * * p<0.01$, ** $p<0.05,{ }^{*} p<0.1$.

previous publications of grant recipients' new coauthors published in 0.7 new research fields as compared to publications of former coauthors, but this figure is even higher for non-recipient applicants (0.9). We conclude that while we observe exploration towards new topics and projects, as captured by the share of self-references, this does not go as far as branching into new fields. ${ }^{16}$ Our finding is in line with the idea that awarded applicants spend the mobility grant to reach out to new colleagues and institutions that excel in their research field. While awarded applicants have the opportunity to select new topics and projects with high potential that are less related to their previous research, these projects, as well as their new coauthors, seem to remain within their area of specialization.

\subsection{Money versus mobility effects}

By design, a mobility grant needs to be used for a specific purpose, i.e., a temporary stay in a different university or research institute. This grant design makes it not possible to perfectly disentangle the effect of receiving research funding from the effect of moving. However, in this section, we discuss additional evidence suggesting that mobility seems to play the main role in our context of analysis.

Empirical evidence shows that the grant has no effect when mobility is not differential, i.e., when the recipients have recently received a previous mobility grant. The Advanced Mobility Scholarship program is the last opportunity to obtain funding to move abroad offered by the SNSF along with the career of a researcher in Switzerland. However, other opportunities exist in the early stages of a researcher's career. Taking advantage of a variable in our data (Early mobility grants), we distinguish applicants who obtained only the advanced mobility grant from those who have previously received funding for an early mobility experience. In the latter case, the advanced mobility grant likely constitutes the prolongation of a previous period abroad. Table 8 reports the results of the main coefficient estimates for the two distinct subpopulations.

Interestingly, applicants in their first mobility experience seem to drive the results. For them, obtaining the grant increases the probability

\footnotetext{
${ }^{16}$ The ASJC classification at the 4-digit level comprises 335 codes. Notably, each researcher in our sample is associated to 6 codes on average. The classification distinguishes, for instance, "Mechanical Engineering" from "Industrial and Manufacturing Engineering", "Biochemistry" from "Biophysics", "Management of Technology and Innovation" from "Strategy and Management". Therefore, a substantial deviation from a research field to another should be captured using this level of aggregation. Nonetheless, exploration of different topics and projects may very well happen within each one of these fields, at a finer grained level, which is what is likely reflected in our results on the share of self-references.
}

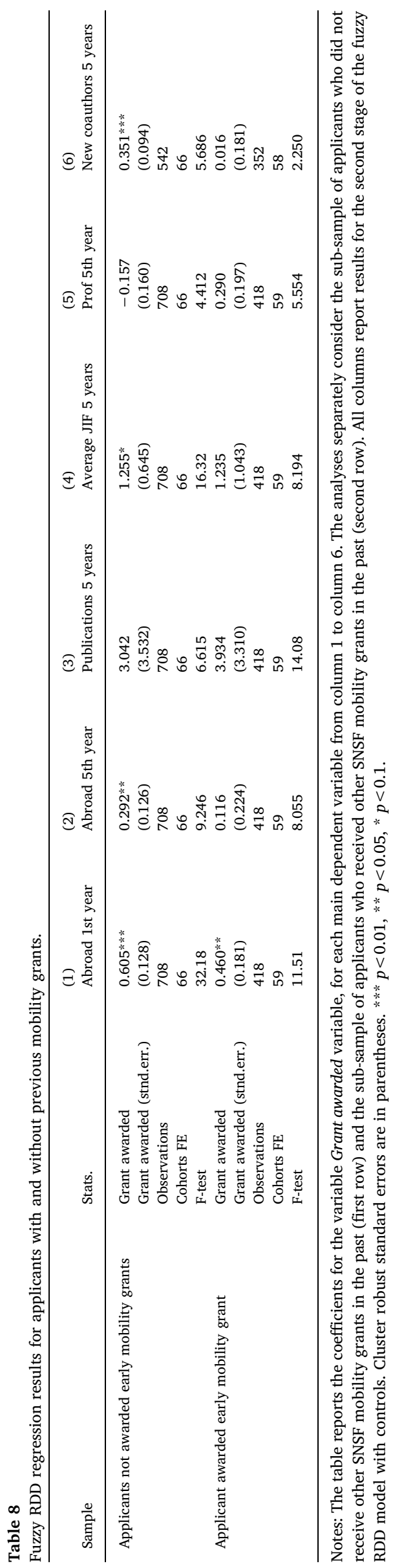


of being abroad in the first year, as well as the fifth year. The likelihood of applicants with early mobility grants being abroad after 5 years is not statistically significant. Moreover, obtaining the grant has a positive impact on the average JIF of the journals where they publish and a positive and stronger effect on the number of new-co-authorships established (+35 pp.). On the contrary, the effect on these variables for applicants with previous mobility grants is negligible. The fact that the results are mainly driven by applicants who did not receive previous mobility grants is in line with the idea that the mobility experience, more than the financial support per se, drives our main results.

Additional qualitative evidence seems to support that the mobility effect dominates the money one. First, it is important to consider that the funding provided by the mobility grant is mostly limited to the researcher's wage, necessary expenses for conference participation, and does not include a research budget (or a relatively small one). There is no retribution gain in being awarded recipient, i.e., the salary paid by the grant is generally lower than the salary for a comparable position in Switzerland and aligned to wages in the destination country. Additionally, we screened manually the curricula of the non-granted applicants that almost received the grant (grade equal 0 ) and remained in Switzerland. Doing this exercise, we observed that those who stayed in Switzerland were capable of securing alternative research funding, and had no evidence of inactivity periods. Most importantly, we verified that receiving the grant does not affect the probability of leaving academia. $^{17}$

\section{Robustness}

We performed a set of analyses to test the robustness of our main results. Following Cattaneo et al. (2015) and Cattaneo et al. (2016), Table 9 presents randomization-based inference estimates at the minimum window around the acceptance threshold. These analyses overcome possible limitations deriving from large-sample approximations in relatively small samples, around the discontinuity threshold. To account for cohorts of applicants fixed effects, we demean the dependent variables by cohort groups' means. The window with values of the grade above and below the acceptance threshold is the narrowest window that we can use with our data. At the same time, this window passes the randomization assumption tests (window selection) based on all covariates, except for "Early mobility grants." This result is equivalent to the analysis presented in Table A-1 and previously discussed in Section 4. We report difference in means estimates, finite sample p-values, and Rosenbaum's confidence intervals under arbitrary interference (Rosenbaum, 2006).

In other robustness analyses ${ }^{18}$ we tested the robustness of the results to our main model specifications in different scenarios: (i) when removing applicants at extreme values of the grade, (ii) when removing "fuzzy observations" (applicants above the threshold who did not receive or used the grants and applicants below the threshold that received the grant), and (iii) when removing applicants that moved abroad despite not having received the grant. Removing applicants at extreme values of the grade yields somewhat weaker results, but still significant and overall equivalent to the scope of our discussion. The results of the other two robustness analyses are consistent with our main model specifications.

\footnotetext{
${ }^{17}$ The grants analyzed in our study, Advanced Postdoc Mobility, are targeting researchers with some years of experience after their $\mathrm{PhD}$ and a high propensity to remain in academia. In our sample, $94 \%$ stay in academia. For this reason we focus our main analysis only on the academic careers. However, we run a set of regressions where we study the likelihood of staying in academia versus going to industry. The results show that being awarded the grant has no effect.

${ }^{18}$ The additional robustness analyses are available upon request.
}

\section{Conclusions}

In this paper, we implement a quasi-experimental research design to evaluate the impact of an international mobility grant program on individual careers. We find that obtaining the grant supports international mobility, both in the short and medium run. The mobility grant does not, to a large extent, crowd-out alternative funding for the same mobility experience. Interestingly, we find that receiving the grant supports mobility beyond the duration of the grant. Nonetheless, after 5 years, the effect is substantially reduced and further decreases in the subsequent years. We then find a positive effect on the average impact factor of the journals where scientists publish, as well as in the number of new research collaborations. The effect on productivity, in terms of the number of publications, and on the likelihood of obtaining a professorship, is not significant. Further investigating the mechanisms, we find that awarded applicants collaborate more likely with new coauthors, of on average higher scientific quality in their fields, and rely less on their previous research. Importantly, we verify that the effect on quality is not limited to publications realized during the period abroad or in collaboration with authors in the host institution. Moreover, the grant has a higher impact on a researcher receiving a mobility grant for the first time.

Our results speak to the literature on research public funding and add to the debate on the mechanisms through which supporting mobility is likely to affect individual outcomes, with implications for policymakers and organizations interested in supporting mobility. In our study, financially supporting international mobility proves to successfully increase initial mobility, which facilitates securing additional funding abroad, and eventually allows the realization of new collaborations and high-quality research projects. Moreover, the risk of leading to excessive permanent migration appears limited. The evidence on research outcomes is compatible with the idea that mobility grants reduce the cost of exploring new collaborations and research projects of high scientific quality within one's field, eventually leading to scientific output of higher quality.

A few caveats are in order. Our results can be generalized to other OECD countries with similar research environments and policy tools. When looking at the outflow of students from Switzerland, the proportion of master's and doctoral graduates who are spending a temporal period abroad (48\% for Switzerland) is comparable with the one of Sweden and Germany (OECD, 2019). The Swiss program studied has commonalities with programs offered by those European countries. While results can be generalized to such similar realities, they are limited to one country and may change in different contexts. For instance, financially promoting mobility in less competitive and less internationalized research environments may lead to a higher rate of permanent migration. The open nature of the Swiss research system may also imply conservative estimates since the exposure to international science is already substantial within the country's borders. In other more closed, insular systems the effects might be greater. Also importantly, different policy tools - such as collaborative research grants (Ayoubi et al., 2017), welcoming institutional policies, immigration policies, quotas of external, and foreign candidates for research positions - may change the contextual factors in which mobility and collaboration take place - for instance, lowering or exacerbating initial mobility costs, favoring or limiting exploration activities - with consequences for the ultimate effects.

In general, researchers' mobility remains a multifaceted phenomenon, and further work might seek to extend our results to other policy programs and countries. The array of possible policies and contextual factors that may determine different forms and consequences of mobility is highly heterogeneous. Causal evidence on the effects of different policy and strategic interventions may be crucial for a deeper understanding of how mobility can be leveraged to enhance science and innovation performance, and for a better comprehension of the phenomenon itself. 
Table 9

Randomization-based estimates at the acceptance threshold.

\begin{tabular}{|c|c|c|c|c|c|c|}
\hline & Abroad 1st year & Abroad 5th year & Publications 5 years & Average JIF 5 years & Prof 5th year & New coauthors 5 years \\
\hline Diff. in means & $0.338 * * *$ & $0.249 * * *$ & -1.946 & $0.913 * *$ & 0.097 & $0.082 * *$ \\
\hline Finite sample p-value & 0.001 & 0.000 & 0.277 & 0.017 & 0.182 & 0.014 \\
\hline Rosenbaum's C.I. 95\% & $(0.226,0.452)$ & $(0.122,0.382)$ & $(-5.470,1.653)$ & $(0.226,1.637)$ & $(-0.035,0.208)$ & $(0.019,0.179)$ \\
\hline N. observations & 280 & 280 & 280 & 280 & 280 & 230 \\
\hline
\end{tabular}

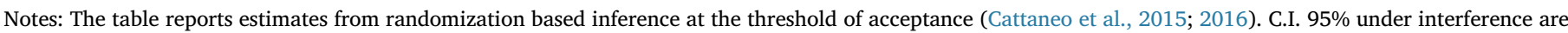

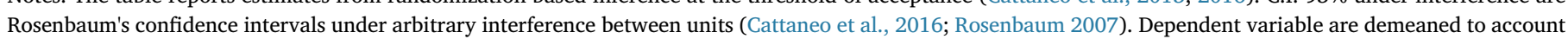
for cohorts fixed effects. ${ }^{* * *} p<0.01,{ }^{* *} p<0.05$, ${ }^{*} p<0.1$.

Table A-1

RDD regression results on covariates.

\begin{tabular}{lll} 
& $\begin{array}{l}\text { I(Grade }>\text { threshold) } \\
\text { Coeff. }\end{array}$ & S.e. \\
\hline Foreign & -0.120 & $(0.0748)$ \\
Female & -0.0366 & $(0.0687)$ \\
Age & 0.234 & $(0.606)$ \\
Publications & -0.121 & $(1.314)$ \\
Citations & -5.856 & $(6.288)$ \\
Average JIF & 0.0841 & $(0.385)$ \\
Coauthors & -18.40 & $(15.67)$ \\
Early mobility grants & $-0.173^{* *}$ & $(0.0689)$ \\
Rank Ph.D. university & 2.189 & $(2.300)$ \\
Rank host university & -3.757 & $(2.751)$ \\
Rank host res. institute & -0.0141 & $(2.000)$ \\
Proposed duration & 2.037 & $(1.579)$ \\
Amount request & 5.237 & $(6.898)$ \\
Dest. US & 0.0296 & $(0.0635)$ \\
Dest. UK & -0.0606 & $(0.0562)$ \\
Dest. Germany & 0.0478 & $(0.0446)$ \\
Dest. France & 0.0524 & $(0.0428)$ \\
Dest. other & -0.0692 & $(0.0798)$ \\
\hline
\end{tabular}

Notes: The table reports coefficients means (Coeff.) and cluster-robust standard errors (S.e.) for the main variable of interest (dummy variable equal to 1 if Grade is higher than the cutoff) from a set of regressions where each control variable is regressed against the RDD model with cohort fixed effects and with clustered standard errors. The number of observations is 1132.

\section{Acknowledgements}

We are indebted to Dominique Foray, Jacques Mairesse, Daniel Sebastiani, and Paula Stephan for their invaluable advice. We also thank Pierpaolo Parrotta, Michele Pezzoni, Reinhilde Veugelers, and the participants of DRUID Conference in Copenhagen, the Workshop on The Organization, Economics and Policy of Scientific Research, BRICK, Collegio Carlo Alberto, and Academy of Management Conference. We also acknowledge the SNSF for having provided us the data and support.

\section{Declaration of Competing Interest}

None.

\section{Appendix A-1}

Table A-1

\section{Appendix A-2}

Table A-2

\section{Appendix A.3. Year by year regressions}

We extend our analyses by providing results for the main outcome variables for every single year separately. Results for the number of publications and the professorship remain not significant and are not reported. We perform the analyses up to the 5th year for the entire sample, and extend it to the 6th and 7th year for the subsample of the cohorts 2003-2010 and 2003-2009, respectively. Due to truncation, the outcome variables for the latest cohorts were not observable in the 6th year (2017 for mobility and professorship and 2018 for publications data) and 7 th year (2018 for mobility and professorship and 2019 for publications data) at the moment of the data collection. The findings allow us to highlight some additional interesting considerations. Results are reported in Table A-3.

The probability of an applicant of being abroad gradually decreasing from the first to the fifth year. Interestingly, the effect remains substantially high and significant, equal to a $29 \mathrm{pp}$. higher probability of being abroad, up to the fourth year (beyond the maximum duration and considerably beyond the average duration of the grant). The effect continues to decrease and becomes gradually insignificant after the 5th year. Looking at the effect on the average JIF, our findings show a positive coefficient in each year following the first. The magnitude of the coefficient reaches the highest value and significance in the 5th year. This result suggests that the investment in a mobility experience may pay off in the medium-long term. However, publication delays of research results, in particular across different scientific disciplines, may also explain this result.

Finally, we find that the effect on collaboration with new coauthors is positive and significant in the 1st and 4th year. Notably, in Table A-3, each 
Table A-2

First-stage regression results in fuzzy RDD model.

\begin{tabular}{|c|c|c|c|}
\hline & $\begin{array}{l}\text { First-stage } \\
\text { regression }\end{array}$ & $\begin{array}{l}\text { First-stage regression } \\
\text { Applicants not } \\
\text { awarded early } \\
\text { mobility grants }\end{array}$ & $\begin{array}{l}\text { First-stage } \\
\text { regression Applicant } \\
\text { awarded early } \\
\text { mobility grant }\end{array}$ \\
\hline \multirow{2}{*}{$\begin{array}{l}\text { I(Grade > } \\
\quad \text { threshold) }\end{array}$} & $0.685^{* k *}$ & $0.718^{* * *}$ & $0.629 * * *$ \\
\hline & $(0.057)$ & $(0.069)$ & $(0.084)$ \\
\hline \multirow[t]{2}{*}{ Grade } & $0.047^{* * * *}$ & $0.044 * *$ & $0.065^{*}$ \\
\hline & $(0.017)$ & $(0.019)$ & $(0.034)$ \\
\hline \multirow{2}{*}{$\begin{array}{c}\text { Grade*I(Grade }> \\
\text { threshold) }\end{array}$} & $0.055^{*}$ & 0.036 & 0.064 \\
\hline & $(0.031)$ & $(0.033)$ & $(0.056)$ \\
\hline \multirow[t]{2}{*}{ Foreign } & -0.007 & -0.001 & -0.010 \\
\hline & $(0.016)$ & $(0.019)$ & $(0.028)$ \\
\hline \multirow[t]{2}{*}{ Female } & -0.004 & 0.012 & -0.030 \\
\hline & $(0.020)$ & $(0.025)$ & $(0.024)$ \\
\hline \multirow[t]{2}{*}{ Age } & -0.004 & -0.005 & -0.001 \\
\hline & $(0.003)$ & $(0.004)$ & $(0.005)$ \\
\hline \multirow[t]{2}{*}{ Publications } & 0.001 & $0.002^{* * * *}$ & -0.002 \\
\hline & $(0.000)$ & $(0.000)$ & $(0.002)$ \\
\hline \multirow[t]{2}{*}{ Citations } & -0.000 & -0.000 & 0.000 \\
\hline & $(0.000)$ & $(0.000)$ & $(0.000)$ \\
\hline \multirow{2}{*}{ Average JIF } & 0.003 & 0.000 & 0.002 \\
\hline & $(0.002)$ & $(0.003)$ & $(0.003)$ \\
\hline \multirow[t]{2}{*}{ Coauthors } & -0.000 & -0.000 & 0.000 \\
\hline & $(0.000)$ & $(0.000)$ & $(0.000)$ \\
\hline \multirow{2}{*}{$\begin{array}{l}\text { Early mobility } \\
\text { grants }\end{array}$} & -0.002 & & -0.007 \\
\hline & $(0.021)$ & & $(0.101)$ \\
\hline \multirow{2}{*}{$\begin{array}{l}\text { Rank PhD } \\
\quad \text { university }\end{array}$} & $0.001^{* * *}$ & $0.002^{* *}$ & 0.001 \\
\hline & $(0.000)$ & $(0.001)$ & $(0.001)$ \\
\hline \multirow{2}{*}{$\begin{array}{l}\text { Rank host } \\
\text { university }\end{array}$} & 0.000 & -0.000 & 0.001 \\
\hline & $(0.000)$ & $(0.001)$ & $(0.001)$ \\
\hline \multirow{2}{*}{$\begin{array}{l}\text { Rank host res. } \\
\text { institute }\end{array}$} & 0.000 & 0.001 & -0.000 \\
\hline & $(0.001)$ & $(0.001)$ & $(0.001)$ \\
\hline \multirow[t]{2}{*}{ Proposed duration } & 0.002 & -0.000 & 0.004 \\
\hline & $(0.002)$ & $(0.002)$ & $(0.003)$ \\
\hline \multirow[t]{2}{*}{ Amount request } & -0.000 & 0.000 & -0.001 \\
\hline & $(0.000)$ & $(0.000)$ & $(0.001)$ \\
\hline $\begin{array}{l}\text { Destination } \\
\quad \text { dummies }\end{array}$ & Yes & Yes & Yes \\
\hline Cohorts FE & Yes & Yes & Yes \\
\hline Obs. & 1132 & 708 & 418 \\
\hline N.Cohorts & 67 & 66 & 59 \\
\hline F-test & 365 & 665 & 229 \\
\hline F-test instr. & 142 & 109 & 56 \\
\hline
\end{tabular}

Notes: The table reports results for the first-stage regression of the two-stage fuzzy RDD models. The dependent variable is Grant awarded. The table also reports the F-test on the excluded instrument, I(Grade $>$ threshold). Cluster-robust standard errors are in parentheses. ${ }^{* * *} p<0.01, * * p<0.05$, * $p<0.1$.

variable is constructed to capture the number of new coauthors in the focal year, relative to all coauthors appearing in any publication up to the year before. For instance, the variable Coauthors for the 4th year counts the number of new coauthors in the 4th year, relative to all coauthors up to the third year. This finding means that the expansion of the network to new coauthors is sustained up to the 4th year. The fact that the coefficient in the 6th year is negative may suggest that after a faster expansion of the network follows a period were the acquisition of new coauthors becomes less likely as compared to authors who expand their network more slowly in the previous years.

\section{Appendix A.4. The heterogeneity of the institute quality}

We further explore the heterogeneity of the main results concerning the ranking position of the university where applicants obtained their Ph.D. and the host institution ranking. We use model specifications where we include interactions not only with Grant awarded and I(Grade $>$ Threshold) but also with the assignment variable (Grade and Grade*I(Grade > Threshold), both in the first and second stage regressions (Hsu and Shen, 2017) (henceforth full interaction models). Interacted variables are centered at the median. We report results using the rank of the institution of the Ph.D. (Table A-4) and the rank of the host institution (Table A-5) as interacting variables separately. We verified that results are the same using a combined variable measuring the difference in rank between the two institutions.

The only positive interaction relates to the probability of obtaining a professorship, implying that the likelihood of obtaining a professorship is higher for applicants having as destination a lower-ranked institution. The overall effect is significant only for the rather extreme values of the interaction variable. Based on evidence from CVs', the most likely explanation seems to be that non-recipients, which had lower-ranked institutions as a destination, have higher chances of finding a professorship position in the same institutions. While partly surprising, we posit that this result is in 
Table A-3

Fuzzy RDD regression results year by year.

\begin{tabular}{|c|c|c|c|c|c|c|c|c|}
\hline Dep. Variable & Stats. & $\begin{array}{l}\text { (1) } \\
\text { 1st year }\end{array}$ & $\begin{array}{l}\text { (2) } \\
\text { 2nd year }\end{array}$ & $\begin{array}{l}\text { (3) } \\
\text { 3rd year }\end{array}$ & $\begin{array}{l}\text { (4) } \\
\text { 4th year }\end{array}$ & $\begin{array}{l}(5) \\
5 \text { th year }\end{array}$ & $\begin{array}{l}\text { (6) } \\
\text { 6th year }\end{array}$ & $\begin{array}{l}\text { (7) } \\
7 \text { th year }\end{array}$ \\
\hline \multirow[t]{4}{*}{ Abroad } & Grant awarded & $0.472^{* * *}$ & $0.334 * k *$ & $0.254 * *$ & $0.290 * *$ & $0.244 *$ & 0.156 & 0.068 \\
\hline & Grant awarded stnd.err. & $(0.105)$ & $(0.104)$ & $(0.110)$ & $(0.124)$ & $(0.128)$ & $(0.127)$ & $(0.144)$ \\
\hline & Obs. (N. Cohorts) & $1132(67)$ & $1132(67)$ & $1132(67)$ & $1132(67)$ & $1132(67)$ & 950 (59) & $791(51)$ \\
\hline & F-test & 35.81 & 25.49 & 15.74 & 9.984 & 9.950 & 9.649 & 15.70 \\
\hline \multirow[t]{4}{*}{ Average JIF } & Grant awarded & 1.129 & $1.042^{*}$ & 0.750 & 1.034 & $1.412^{* *}$ & 0.591 & 0.662 \\
\hline & Grant awarded stnd.err. & $(0.700)$ & $(0.577)$ & $(0.512)$ & $(0.702)$ & $(0.653)$ & $(0.579)$ & $(0.662)$ \\
\hline & Obs. (N. Cohorts) & $1132(67)$ & $1132(67)$ & $1132(67)$ & $1132(67)$ & $1132(67)$ & 950 (59) & $791(51)$ \\
\hline & F-test & 6.719 & 10.70 & 9.625 & 4.516 & 4.743 & 3.779 & 2.313 \\
\hline \multirow[t]{4}{*}{ Coauthors } & Grant awarded & $0.123^{* *}$ & -0.028 & 0.099 & $0.092 *$ & 0.037 & $-0.097 * *$ & 0.002 \\
\hline & Grant awarded stnd.err. & $(0.058)$ & $(0.054)$ & $(0.061)$ & $(0.049)$ & $(0.040)$ & $(0.049)$ & $(0.053)$ \\
\hline & Obs. (N. Cohorts) & $900(67)$ & $900(67)$ & $900(67)$ & $900(67)$ & $900(67)$ & 739 (59) & $650(51)$ \\
\hline & F-test & 2.330 & 3.248 & 3.802 & 1.790 & 2.643 & 1.770 & 1.509 \\
\hline
\end{tabular}

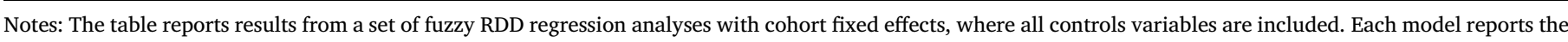

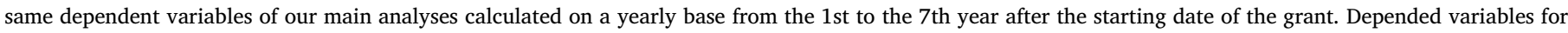

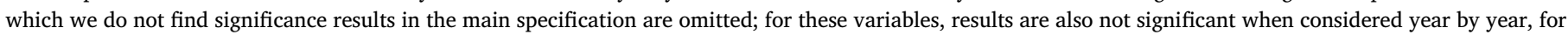

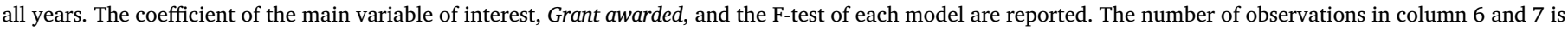
lower due to truncation in the latest cohorts of our sample. Cluster-robust standard errors are in parentheses. ${ }^{* *} p<0.01$, ${ }^{* *} p<0.05$, ${ }^{*} p<0.1$.

line with the mechanisms we have explored and found evidence for in the paper. Moreover, we note that all applicants, at the cutoff margin, are matched with institutions of similar and high quality in their field of research, yielding limited variance in the research quality of the institutions. The decision of the host institution results from the applicants' choices and that, in principle, all awarded applicants apply and are selected to spend a period in a host institution that is optimal for their research.

\section{Appendix A-4}

Table A-4

\section{Appendix A-5}

Table A-5

Table A-4

Heterogeneity of ranking position of the university where the applicant obtained her $\mathrm{PhD}$.

\begin{tabular}{lll}
\hline & $\begin{array}{l}\text { I(Grade }>\text { threshold) } \\
\text { Coeff. }\end{array}$ & S.e. \\
\hline Foreign & -0.107 & $(0.071)$ \\
Female & 0.007 & $(0.071)$ \\
Age & -0.191 & $(0.330)$ \\
Publications & -0.420 & $(1.141)$ \\
Citations & -9.082 & $(6.710)$ \\
Average JIF & -0.290 & $(0.379)$ \\
Coauthors & $-10.249^{*}$ & $(5.533)$ \\
Early mobility grants & $-0.161^{* *}$ & $(0.062)$ \\
Rank PhD university & 0.919 & $(1.961)$ \\
Rank host university & -2.540 & $(2.737)$ \\
Rank host res. institute & 2.045 & $(1.801)$ \\
Proposed duration & 0.061 & $(0.061)$ \\
Amount request & -0.050 & $(0.049)$ \\
Dest. US & -0.033 & $(0.040)$ \\
Dest. UK & -0.017 & $(0.033)$ \\
Dest. Germany & 0.039 & $(0.056)$ \\
Dest. France & 1.626 & $(1.264)$ \\
Dest. other & 4.581 & $(5.613)$ \\
\end{tabular}

Notes: The table reports the coefficients for the variable Grant awarded and for the interaction effect with Rank Ph.D. university, for each main dependent variable from column 1 to column 6 . All columns report results for the second stage of the fuzzy RDD model with controls. The specification includes: the interaction with the main variable, Grant awarded, in the second stage, and as additional dependent variables of the first stage; the interaction of the interaction variable with Grade and Grade*I(Grade > threshold) both in the first and in the second stage regressions, and the interaction with the variable $I$ (Grade $>$ threshold) as additional excluded instrument in the first stage. Cluster-robust standard errors are in parentheses. $* * * p<0.01,{ }^{* *} p<0.05, * p<0.1$. 
Table A-5

Exploring the impact of the ranking position of the host institute.

\begin{tabular}{|c|c|c|c|c|c|c|}
\hline Grant awarded by field & $\begin{array}{l}\text { (1) } \\
\text { Abroad 1st year }\end{array}$ & $\begin{array}{l}\text { (2) } \\
\text { Abroad 5th year }\end{array}$ & $\begin{array}{l}\text { (3) } \\
\text { Publications } 5 \text { years }\end{array}$ & $\begin{array}{l}\text { (4) } \\
\text { Average JIF } 5 \text { years }\end{array}$ & $\begin{array}{l}\text { (5) } \\
\text { Prof 5th year }\end{array}$ & $\begin{array}{l}\text { (6) } \\
\text { New coauthors } 5 \text { years }\end{array}$ \\
\hline Medicine and health & $\begin{array}{l}0.440 * * * \\
(0.110)\end{array}$ & $\begin{array}{l}0.175 \\
(0.134)\end{array}$ & $\begin{array}{l}2.627 \\
(4.404)\end{array}$ & $\begin{array}{l}1.612^{* *} \\
(0.689)\end{array}$ & $\begin{array}{l}-0.180 \\
(0.119)\end{array}$ & $\begin{array}{l}0.268^{* * *} \\
(0.075)\end{array}$ \\
\hline Social sciences & $\begin{array}{l}0.550 * * * \\
(0.135)\end{array}$ & $\begin{array}{l}0.224 \\
(0.170)\end{array}$ & $\begin{array}{l}2.733 \\
(2.212)\end{array}$ & $\begin{array}{l}0.475 \\
(0.517)\end{array}$ & $\begin{array}{l}0.117 \\
(0.110)\end{array}$ & $\begin{array}{l}-0.005 \\
(0.080)\end{array}$ \\
\hline Natural sc. and Eng. & $\begin{array}{l}0.508^{* * *} \\
(0.130)\end{array}$ & $\begin{array}{l}0.330^{* *} \\
(0.138)\end{array}$ & $\begin{array}{l}8.539 * * \\
(3.574)\end{array}$ & $\begin{array}{l}1.207^{* *} \\
(0.541)\end{array}$ & $\begin{array}{l}0.012 \\
(0.120)\end{array}$ & $\begin{array}{l}0.187^{* *} \\
(0.089)\end{array}$ \\
\hline Life science & $\begin{array}{l}0.449 * * * \\
(0.120)\end{array}$ & $\begin{array}{l}0.273^{*} \\
(0.161)\end{array}$ & $\begin{array}{l}1.534 \\
(2.406)\end{array}$ & $\begin{array}{l}1.574 * \\
(0.912)\end{array}$ & $\begin{array}{l}0.090 \\
(0.111)\end{array}$ & $\begin{array}{l}0.145^{* *} \\
(0.073)\end{array}$ \\
\hline Controls & Yes & Yes & Yes & Yes & Yes & Yes \\
\hline Destination dummies & Yes & Yes & Yes & Yes & Yes & Yes \\
\hline Cohorts FE & Yes & Yes & Yes & Yes & Yes & Yes \\
\hline Obs. & 1132 & 1132 & 1132 & 1132 & 1132 & 900 \\
\hline N.Cohorts & 67 & 67 & 67 & 67 & 67 & 67 \\
\hline F-test & 35.63 & 9.567 & 8.298 & 21 & 8.616 & 4.760 \\
\hline
\end{tabular}

Notes: The table reports the coefficients for the variable Grant awarded and for the interaction effect of Rank host, for each main dependent variable from column 1 to column 6. Rank host is obtained by combining the variables Rank host university and Rank host res. Institute. The specification includes: the interaction with the main variable, Grant awarded, in the second stage, and as additional dependent variables of the first stage; the interaction of the interaction variable with Grade and Grade*I(Grade $>$ threshold) both in the first and in the second stage regressions, and the interaction with the variable I(Grade $>$ threshold) as additional excluded instrument in the first stage. All columns report results for the second stage of the fuzzy RDD model with controls. Cluster-robust standard errors are in parentheses. $* * * p<0.01, * * p<0.05, * p<0.1$.

\section{References}

Ackers, L., 2005. Moving people and knowledge: scientific mobility in the European Union. Int. Migr. 43 (5), 99-131.

Adams, W., Douglas, P.H., 1968. The Brain Drain. Macmillan, New York.

Angrist, J.D., Lavy, V., 1999. Using maimodines' rule to estimate the effect of class size on scholastic achievement. Q. J. Econ. 114 (2), 533-575.

Arora, A., Gambardella, A., 2005. The impact of NSF support on basic research in economics. Ann. Econ. Stat. 91-117 79/80(Contributions in memory of Zvi Griliches).

Auriol, L., 2010. In: Careers of Doctorate Holders: Employment and Mobility Patterns, OECD Science, Technology and Industry Working Papers.

Ayoubi, C., Pezzoni, M., Visentin, F., 2017. At the origins of learning: absorbing knowledge flows from within the team. J. Econ. Behav. Organ. 134, 374-387.

Azoulay, P., Graff Zivin, J.S., Manso, G., 2011. Incentives and creativity: evidence from the academic life sciences. RAND J. Econ. 42 (3), 527-554.

Baruffaldi, S.H., Landoni, P., 2012. Return mobility and scientific productivity of researchers working abroad: the role of home country linkages. Res. Policy 41 (9), 1655-1665.

Black, S.E., 1999. Do better schools matter? Parental valuation of elementary education. Quart. J. Econ. 114 (2), 577-599.

Cattaneo, M.D., Arbor, A., Titiunik, R., Vazquez-Bare, G., 2016. Inference in regression discontinuity designs under local randomization. Stata J. http://www-personal. umich.edu/ March 29, 2020.

Cattaneo, M.D., Frandsen, B.R., Titiunik, R., 2015. Randomization inference in the regression discontinuity design: an application to party advantages in the U.S. senate. J. Causal Inference 3 (1), 1-24.

Fernández-Zubieta, A., Geuna, A., Lawson, C., 2016. Productivity pay-offs from academic mobility: should I stay or should I go? Ind. Corp. Change 25 (1), 91-114.

Franzoni, C., Scellato, G., Stephan, P.E., 2012. Foreign-born scientists: mobility patterns for 16 countries. Nat. Biotechnol. 30 (12), 1250-1253.

Franzoni, C., Scellato, G., Stephan, P.E., 2014. The mover's advantage: the superior performance of migrant scientists. Econ. Lett. 122 (1), 89-93.

Gaulé, P., 2014. Who comes back and when? Return migration decisions of academic scientists. Econ. Lett. 124 (3), 461-464.

Gaulé, P., Piacentini, M., 2013. Immigration and innovation: Chinese graduate students in US universities. Rev. Econ. Stat. 95 (2), 698-701.

Gerritsen, S., Plug, E., Van der Wiel, K., 2013. Up or out? How individual Research Grants Affect Academic Careers in the Netherlands. Bureau for Economic Policy Analysis, CPB Netherlands.

Hoisl, K., 2007. Tracing mobile inventors-the causality between inventor mobility and inventor productivity. Res. Policy 36 (5), 619-636.

Howell, S.T., 2017. Financing Innovation: evidence from R\&D grants. Am. Econ. Rev. 107 (4), 1136-1164.

Hunter, R.S., Oswald, A.J., Charlton, B.G., 2009. The elite brain drain*. Econ. J. 119
(538), F231-F251.

Jacob, B.A., Lefgren, L., 2011. The impact of research grant funding on scientific productivity. J. Public Econ. 95 (9-10), 1168-1177.

Jaffe, A.B., 2002. Building programme evaluation into the design of public researchsupport programmes. Oxf. Rev. Econ. Policy 18 (1), 22-34.

Kahn, S., MacGarvie, M., 2012. The effects of the foreign fulbright program on knowledge creation in science and engineering. The Rate and Direction of Inventive Activity Revisited. University of Chicago Press, pp. 161-197.

Lalive, R., Parrotta, P., 2017. How does pension eligibility affect labor supply in couples? Labour Econ. 46, 177-188.

Lanser, D., van Dalen, R., 2013. The Effects of Research Grants on Scientific Productivity and Utilisation. Bureau for Economic Policy Analysis, CPB Netherlands.

Meyer, J.-.B.2003. Policy implications of the brain drain's changing face. Policy Brief, Science and Development Network.

Myers, K., 2018. The Elasticity of Science. No. 3176991. SSRN.

OECD, 2018. Education at a Glance. 2018.

OECD, 2019. Education at a Glance. 2019.

Oosterbeek, H., Webbink, D., 2011. Does studying abroad induce a brain drain? Economica 78 (310), 347-366.

Oyer, P., 2006. Initial labor market conditions and long-term outcomes for economists. J. Econ. Perspect.s 20 (3), 143-160.

Parey, M., Waldinger, F., 2011. Studying abroad and the effect on international labour market mobility: evidence from the introduction of ERASMUS. Econ. J. 121 (551), 194-222.

Pierson, A.S., Cotgreave, P., 2000. Citation figures suggest that the UK brain drain is a genuine problem. Nature 407 (6800), 13.

Ponzo, M., Scoppa, V., 2010. The use of informal networks in Italy: efficiency or favoritism? J. Socio. Econ. 39 (1), 89-99.

Rosenbaum, P.R., 2007. Interference between units in randomized experiments. J. Am. Stat. Assoc. 102 (477), 191-200.

Saxenian, A., 2005. From brain drain to brain circulation: transnational communities and regional upgrading in India and China. Stud. Compar. Int. Dev. 40 (2), 35-61.

Saxenian, A., 2007. The New Argonauts: Regional Advantage in a Global Economy. Harvard University Press.

Scellato, G., Franzoni, C., Stephan, P.E., 2015. Migrant scientists and international networks. Res. Policy 44 (1), 108-120.

Stephan, P.E., 2012. How Economics Shapes Science. Harvard University Press.

Stephan, P.E., Levin, S.G., 2001. Exceptional contributions to US science by the foreignborn and foreign-educated. Popul. Res. Policy Rev. 20 (1), 59-79.

Van Noorden, R., 2012. Global mobility: science on the move. Nature 490 (7420), 326-329.

Zhao, B., Ziedonis, R.H., 2012. State Governments as Financiers of Technology Startups: Implications for Firm Performance. SSRN. 